\title{
Excitation-Emission Matrix Spectroscopy for Analysis of Chemical Composition of Combustion Generated Particulate Matter
}

\author{
Gaurav Mahamuni ${ }^{1}$, Jay Rutherford ${ }^{2}$, Justin Davis ${ }^{3}$, Eric Molnar ${ }^{1}$, Jonathan D. Posner ${ }^{1,2}$, \\ Edmund Seto ${ }^{5}$, Gregory Korshin ${ }^{4}$, Igor Novosselov ${ }^{1,5,6}$ \\ ${ }^{1}$ University of Washington, Mechanical Engineering, Seattle, WA 98195 \\ ${ }^{2}$ University of Washington, Chemical Engineering, Seattle, WA 98195 \\ ${ }^{3}$ University of Washington, Molecular Engineering, Seattle, WA 98195 \\ ${ }^{4}$ University of Washington, Civil and Environmental Engineering, Seattle, WA 98195 \\ ${ }^{5}$ University of Washington, Environmental and Occupational Health Sciences, Seattle, WA \\ 98195
}

${ }^{6}$ University of Washington, Institute for Nano-Engineered Systems, Seattle, WA 98195

\section{Supplemental Information}

Number of Pages: 26

Number of Figures: 25

Number of Table: 1 


\section{Inverted Gravity Flame Reactor (IGFR)}
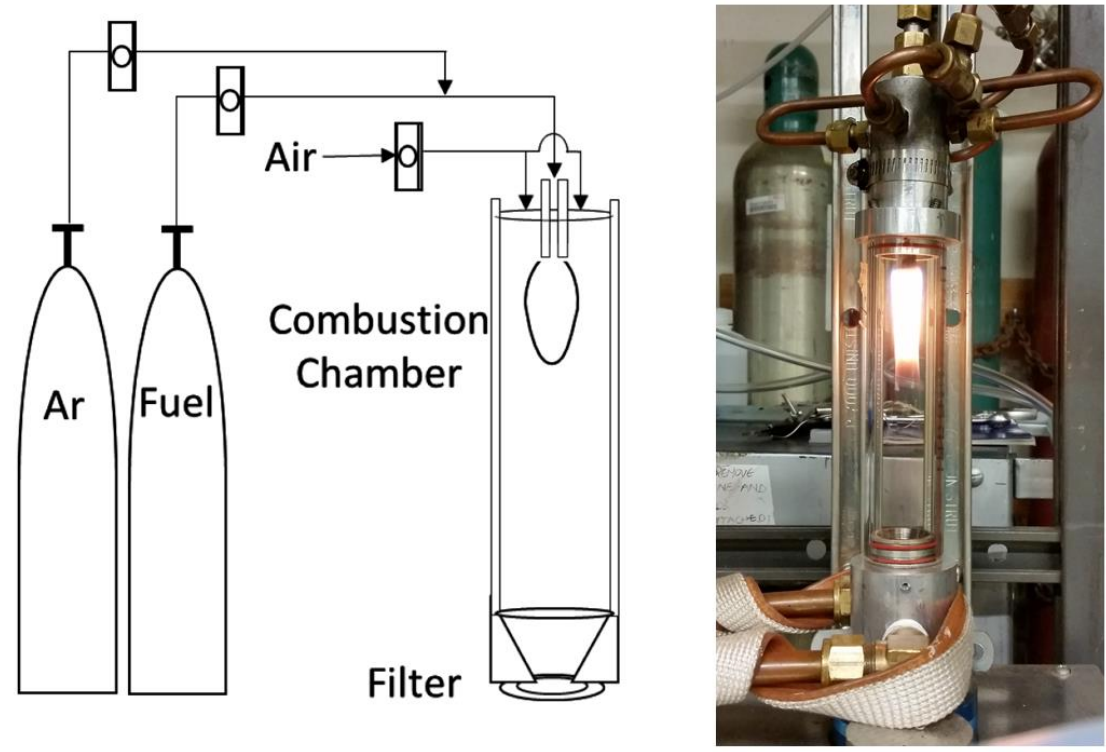

Figure S1: IGFR operating principle (left) and IGFR image (right). Fuel is diluted with argon with different dilution ratios. Soot produced in the flame is collected at the bottom of the combustion chamber 


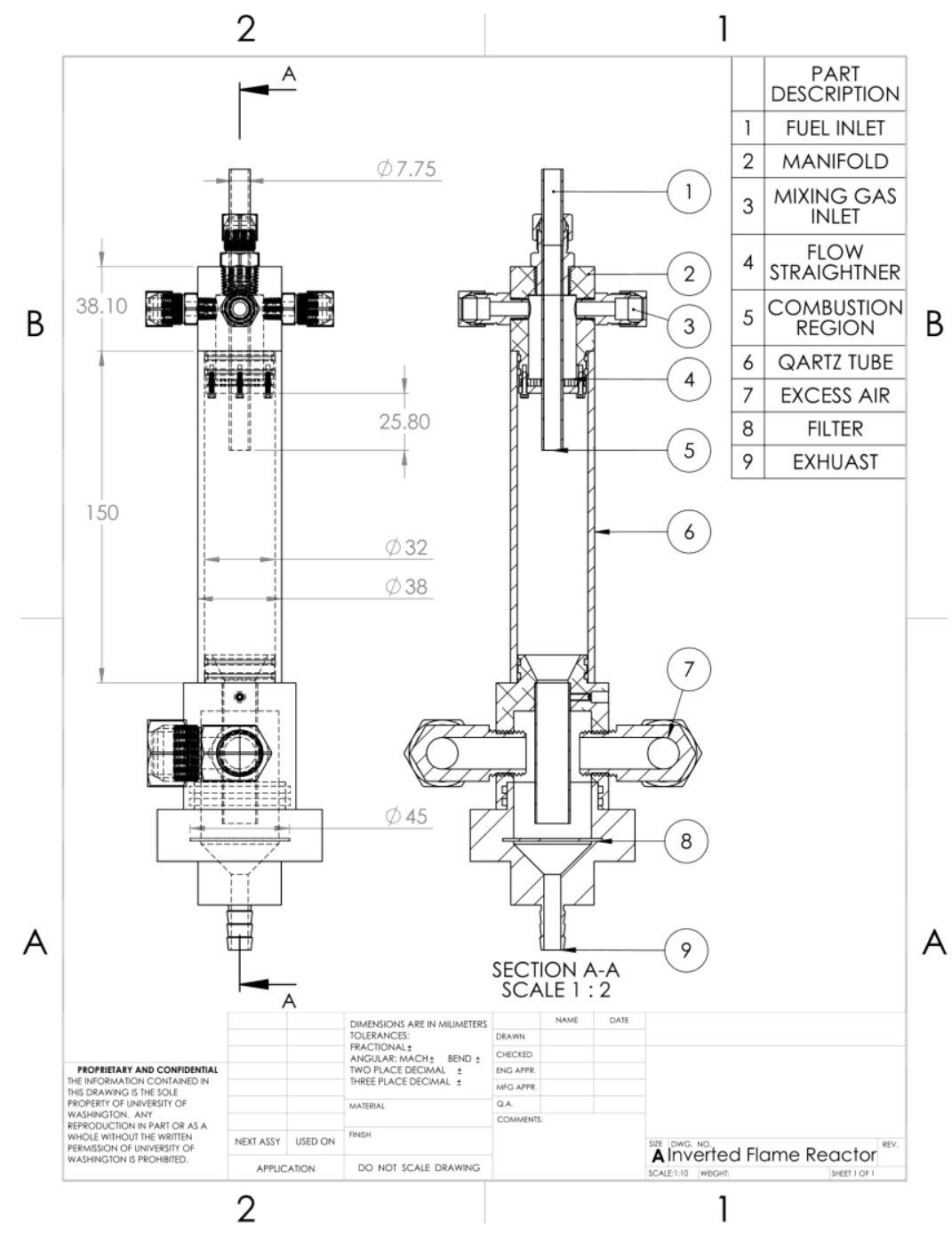

Figure S2: Design of the IGFR combustion chamber. 


\section{Sample Conditions and Analysis}

Table S1: Experimental conditions for different samples and \# samples used for different analysis techniques

\begin{tabular}{|c|c|c|c|c|c|c|}
\hline Fuel & $\begin{array}{c}\text { Dilution } \\
\text { Ratio }\end{array}$ & $\begin{array}{c}\text { Duration } \\
\text { of } \\
\text { Sampling } \\
(\mathbf{m i n})\end{array}$ & $\begin{array}{c}\text { Global } \\
\text { Equivalence } \\
\text { Ratio } \\
(\boldsymbol{\varphi})\end{array}$ & $\begin{array}{c}\text { \# samples } \\
\text { for TOC } \\
\text { analysis }\end{array}$ & $\begin{array}{c}\text { \# samples } \\
\text { for } \\
\text { GCMS } \\
\text { analysis }\end{array}$ & $\begin{array}{c}\text { \# samples } \\
\text { for EEM } \\
\text { analysis }\end{array}$ \\
\hline Ethylene & 0.9 & 120 & 0.65 & 1 & 1 & 1 \\
\hline Ethylene & 0.85 & 15 & 0.65 & 1 & 1 & 1 \\
\hline Ethylene & 0.8 & 15 & 0.65 & - & 3 & 3 \\
\hline Ethylene & 0.67 & 2 & 0.65 & 1 & 2 & 2 \\
\hline Ethylene & 0.5 & 0.5 & 0.65 & 1 & 1 & 1 \\
\hline Ethylene & 0 & 0.33 & 0.65 & 1 & 3 & 3 \\
\hline Ethane & 0.85 & 120 & 0.8 & 1 & 1 & 1 \\
\hline Ethane & 0.8 & 30 & 0.8 & 1 & 1 & 1 \\
\hline Ethane & 0.67 & 5 & 0.8 & 1 & 1 & 1 \\
\hline Ethane & 0.6 & 3 & 0.8 & - & 1 & 1 \\
\hline Ethane & 0.5 & 2 & 0.8 & 1 & 1 & 1 \\
\hline Ethane & 0.25 & 1 & 0.8 & - & 2 & 2 \\
\hline Ethane & 0 & 0.5 & 0.8 & 1 & 2 & 2 \\
\hline
\end{tabular}

\section{Maximum Flame Temperature $\left(T_{\max }\right)$}

Flame temperature affects the condensation, coalescence, transport, carbonization, and aggregation rates during soot formation. Flame temperatures were measured using an uncoated Rtype thermocouple (P13R-003 - wire diameter $0.075 \mathrm{~mm}$, bead-head diameter $(d) 0.17 \mathrm{~mm}$ via optical microscopy). Due to the competing radiative and conductive heat transfer, the thermocouple reached an equilibrium point lower than the flame temperature. Therefore, thermocouple measurements $\left(T_{T C}\right)$ were corrected following previously used radiation correction methods. ${ }^{1,2}$ Heat loss from conduction down the thermocouple wire was neglected. The Nusselt number $(\mathrm{Nu})$ was approximated as that of a sphere. For diluted flames, the relationship between thermal conductivity $(k)$ and flame temperature $(T)$ is linear given by (1).

$$
k=\frac{55.4 T_{\text {cor }}+1228.9}{10^{6}}
$$

The emissivity $(\boldsymbol{\varepsilon})$ of the thermocouple is dependent on its temperature and material. Since the Rtype thermocouple is a Platinum (Pt) wire and a 13\% Rhodium $(\boldsymbol{R} \boldsymbol{h}) / \boldsymbol{P t}$ wire, the $\boldsymbol{\varepsilon}$ values for an S-type $(\boldsymbol{P t}-10 \% \boldsymbol{R h} / \boldsymbol{P t})$ thermocouple are assumed to be representative of the R-type thermocouple and are given by (2) and (3). The arithmetic average $\varepsilon$ value of the two wires was 
used to obtain $\boldsymbol{\varepsilon}$ of the thermocouple $\left(\boldsymbol{\varepsilon}_{\boldsymbol{T} \boldsymbol{C}}\right)(4){ }^{3}$ (5) was used to calculate corrected flame temperature $\left(\boldsymbol{T}_{\boldsymbol{c o r}}\right)$. An iterative function solved for $\boldsymbol{k}$ alternatively based on $\boldsymbol{T}_{\boldsymbol{T C}}$ measurements.

$$
\begin{gathered}
\varepsilon_{P t}=0.136 \ln \left(T_{T C}\right)-0.8 \\
\varepsilon_{P t, 10 \% R h}=0.135 \ln \left(T_{T C}\right)-0.78 \\
\varepsilon_{T C}=\frac{\varepsilon_{P t, 10 \% R h}+\varepsilon_{P t}}{2} \\
T_{c o r}=T_{T C}+\frac{\sigma \varepsilon_{T C}\left(T_{T C}^{4}-T_{a m b}^{4}\right) d}{(k)(N u)}
\end{gathered}
$$

As the thermocouple is placed inside a sooting flame, thermophoresis drives soot particles to deposit on the thermocouple, increasing $\varepsilon$ and $d$. However, it was assumed that soot deposition is negligible because the environment was oxidative. ${ }^{4}$ Additionally, a rapid thermocouple insertion technique was used to reduce temperature correction error. ${ }^{3}$

Maximum flame temperature, $T_{\max }$, is the primary flame characterization explored in this work. The measurement method is based on two fundamental assumptions of flame structure. First, the axisymmetric nature of co-flow flames reduces the temperature field dimension, i.e., temperature measurements along one side represent all azimuthal temperatures at that radial and axial position. Second, the flame front of a diffusion flame is the location of local stoichiometric mixture fraction and peak radial temperature. For each flame condition, an axial profile of flame front temperatures is built from measurements at a $5 \mathrm{~mm}$ resolution. The maximum value of the axial profile determines $T_{\max }$.

The flame temperature in the IGFR is measured with a bare wire thermocouple attached to a stepper motor (0.9-degree rotation per step) on a vertical stage. A microprocessor is programmed to periodically move the exposed junction of the thermocouple from the sheath air region into the flame. Thermocouple junction exposure to the flame is 2.5 seconds. The thermal response time-step, $\tau_{\mathrm{Tc}}$, of the P13R-003 thermocouple is less than $200 \mathrm{~ms}$. The duration of measurement $(2.5 \mathrm{~s})$ allows for thermal equilibrium while mitigating possible soot deposition. Soot deposition is minimal in the hightemperature oxidative region and at axial positions near reactor inlet. For low dilution flames and downstream positions in the flame, soot escapes the flame front boundary and soot deposition is more likely.

The frequency of measurement is limited by the acquisition module at $200 \mathrm{~ms}$ (OMEGA TC-08). The recorded value for each axial measurement along the flame front is determined from the maximum of $\sim 10$ measurements. The axial position is varied by adjusting the linear stage at $5 \mathrm{~mm}$ increments from the end of the fuel inlet tube to the end of the visible flame. Thermocouple 
measurements are recorded by acquisition software (PicoLog Beta 6 ) in Celsius. The R-type thermocouple has a tolerance of $0.25 \%$ of measured value (e.g. $3.75 \mathrm{C}$ for $1500 \mathrm{C}$ ). The acquisition module has an additional tolerance of $0.5 \mathrm{C}$ plus $0.2 \%$ of the measured value. Measurement values are converted to Kelvin before radiation correction.

\section{Temperature at the Maximum Soot Radiation Location $\left(T^{*}\right)$}

To determine the temperature at the maximum soot radiation location $\left(T^{*}\right)$, the temperature measurements recorded along the axis at the flame fronts were used. The axial temperature profile along the flame front was obtained for each flame condition using linear interpolation. This temperature profile was used to estimate the temperature at the maximum soot radiation location $\left(T^{*}\right)$, as described in the next section.

$T_{\max }$ generally does not occur in the sooting region of the flame. Thus, to evaluate the soot temperature, the axial flame temperature profiles were used to identify the gas temperature of the maximum soot radiation region that corresponds to the highest soot temperature. The temperature in the vicinity of the maximum soot radiation was determined based on flame images for each flame condition. Digital images of flames were captured with a Nikon DSLR 5100 in manual mode. Aperture, focal length, and sensitivity were kept constant and the shutter speed was adjusted to vary the exposure. Two laser pointers were used to reference the location of the inlet nozzle location and a location $8 \mathrm{~mm}$ downstream of the nozzle in the axis. A python script was used to extract the red layer of the RGB image and evaluate the location of pixels with the top 5\% intensity along the centreline of the flame to approximate the region of high luminosity. Temperatures at the endpoints of the top 5\% intensity line were estimated based on the temperature profile obtained from the temperature measurements taken along the flame axis. $T^{*}$ is reported as the average of the temperatures estimated at the two endpoints, as shown in Figure S3. 
Ethane $T_{\max }=1883.2 \mathrm{~K}$

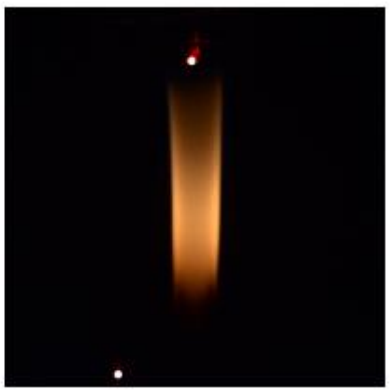

Flame Image with Laser Points

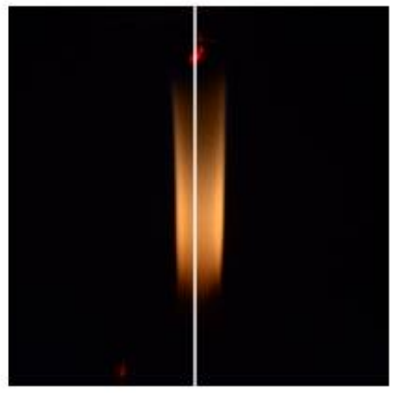

Flame Image with Centerline

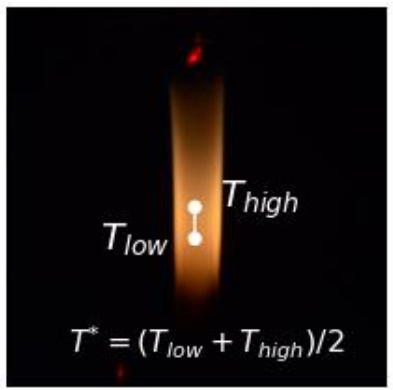

Flame Image with Top 5\% Intensity Location along the Centerline

Figure S3: The python script used to estimate $T^{*}$ detects the two reference laser points in the flame image (distance between the laser points is $8 \mathrm{~mm}$ ) (left), evaluates the location of pixels with top $5 \%$ intensity in the red layer of the image along the centerline (shown in the middle), interpolates the thermocouple temperature measurements to estimate $T_{\text {low }}$ and $T_{\text {high }}$ based on the location of the endpoints of the top 5\% intensity line (right), and reports $T^{*}$ as the average of $T_{\text {low }}$ and $T_{\text {high }}$.

Figure S4 (left) shows the variation of $T^{*}$ with dilution for both ethylene and ethane. $T^{*}$ decreases with an increase in Ar dilution except for an Ar dilution increase from 0.67 to 0.8 for ethylene where $T^{*}$ increases. This indicates that the temperature experienced by the soot in the flame decreases with an increase in Ar dilution. Figure S4 (right) shows the variation of $T^{*}$ vs. $T_{\max }$ for both ethylene and ethane. The variation can be approximated as a linear relationship. Although $T^{*}$ can be used for the characterization of each flame, there is a lot of uncertainty in terms of estimating the range of highest temperatures experienced by the soot in the flame. The radial temperature variation for each axial location is rapid and can cause an error in maximum temperature measurement for each axial location. Based on the previously reported modeling results for laminar diffusion flames, the radial location of the maximum soot concentration is shifted 1-2 mm towards the axis of symmetry from the stoichiometric flame temperature and temperature correction associated with this radial shift is likely to be in $10 \mathrm{~K}-650 \mathrm{~K}^{2,5-8}$ Also, high luminosity in flame images is due to a combination of gas temperature and presence of soot. Hence, temperatures estimated in the region of high luminosity are only an approximation of the highest temperatures experienced by the soot since it assumes that most of the soot is present in the region of high luminosity. Hence, we provide an approximate range of temperatures between $T_{\text {low }}$ and $T_{\text {high }}$ that the soot experiences as highest temperatures in the flame and $T^{*}$ as the average estimate of that range. 

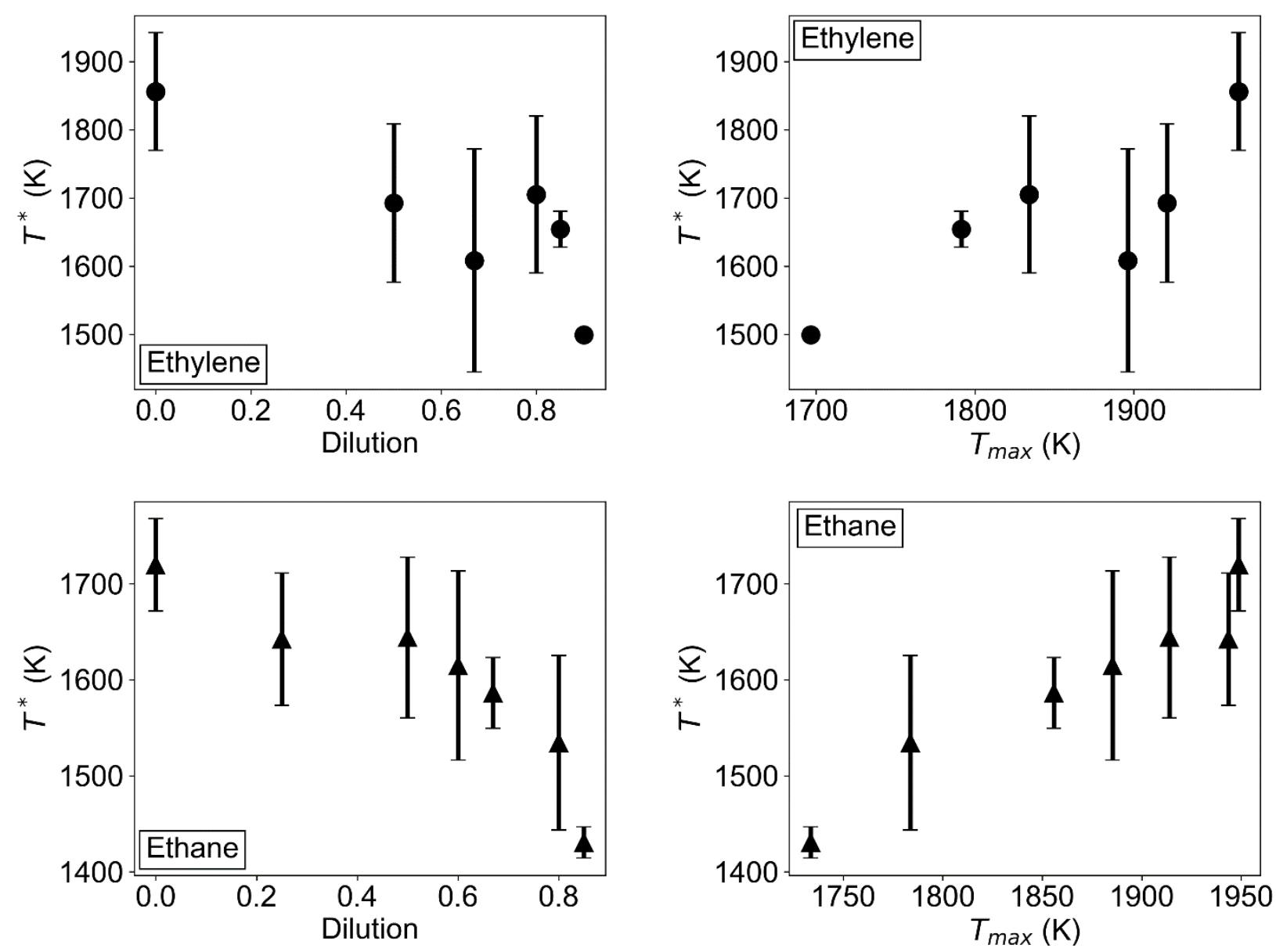

Figure S4: The temperature at the maximum soot radiation location $\left(T^{*}\right)$ is denoted by the midpoint of the temperature range bar. The endpoints of the temperature range bar are $T_{\text {low }}$ and $T_{\text {high }} . T^{*}$ decreases with increasing Ar dilution, in general, for both ethylene and ethane except for an increase in $T^{*}$ when the Ar dilution increases from 0.67 to 0.8 for ethylene (left). $T^{*}$ increases linearly with $T_{\max }$ for both fuels (right). 


\section{GCMS Analysis Method}

\begin{tabular}{|c|c|c|c|c|c|c|c|}
\hline PAH & & Structure & High/Low MW & PAH & & Structure & High/Low MW \\
\hline $\begin{array}{l}\text { Naphthalene } \\
\text { (NA) }\end{array}$ & $\begin{array}{c}\mathrm{C}_{10} \mathrm{H}_{8} \\
128\end{array}$ & & Low & $\begin{array}{l}\text { Benzo[b] } \\
\text { fluoranthene } \\
(\mathrm{BbF})\end{array}$ & $\begin{array}{c}\mathrm{C}_{20} \mathrm{H}_{12} \\
252\end{array}$ & & $\operatorname{High}^{\#}$ \\
\hline $\begin{array}{l}\text { Acenaphthene } \\
\text { (AC) }\end{array}$ & $\begin{array}{c}\mathrm{C}_{12} \mathrm{H}_{10} \\
155\end{array}$ & & Low * & $\begin{array}{l}\text { Benzo[j] } \\
\text { fluoranthene } \\
(\mathrm{BbF})\end{array}$ & $\begin{array}{c}\mathrm{C}_{20} \mathrm{H}_{12} \\
252\end{array}$ & & $\operatorname{High}^{\#}$ \\
\hline $\begin{array}{l}\text { Acenapthylene } \\
(\mathrm{ACN})\end{array}$ & $\begin{array}{c}\mathrm{C}_{12} \mathrm{H}_{8} \\
152\end{array}$ & & Low & $\begin{array}{l}\text { Benzo[k] } \\
\text { fluoranthene } \\
(\mathrm{BkF})\end{array}$ & $\begin{array}{c}\mathrm{C}_{20} \mathrm{H}_{12} \\
252\end{array}$ & & $\operatorname{High}^{\#}$ \\
\hline $\begin{array}{l}\text { Fluorene } \\
\text { (FL) }\end{array}$ & $\begin{array}{c}\mathrm{C}_{13} \mathrm{H}_{10} \\
166\end{array}$ & & Low & $\begin{array}{l}\text { Benzo[a]pyrene } \\
\text { (BaP) }\end{array}$ & $\begin{array}{c}\mathrm{C}_{20} \mathrm{H}_{12} \\
252\end{array}$ & & High \\
\hline $\begin{array}{l}\text { Phenanthrene } \\
\text { (PHE) }\end{array}$ & $\begin{array}{c}\mathrm{C}_{14} \mathrm{H}_{10} \\
178\end{array}$ & & Low & $\begin{array}{l}\text { Benzo[ghi]- } \\
\text { perylene } \\
(\mathrm{BgP})\end{array}$ & $\begin{array}{c}\mathrm{C}_{22} \mathrm{H}_{12} \\
276\end{array}$ & & High \\
\hline $\begin{array}{l}\text { Anthracene } \\
(\mathrm{AN})\end{array}$ & $\begin{array}{c}\mathrm{C}_{14} \mathrm{H}_{10} \\
178\end{array}$ & & Low & $\begin{array}{l}\text { Indeno[1,2,3-cd }] \text { - } \\
\text { pyrene } \\
\text { (IP) }\end{array}$ & $\begin{array}{c}\mathrm{C}_{22} \mathrm{H}_{12} \\
276\end{array}$ & & High \\
\hline $\begin{array}{l}\text { Fluoranthene } \\
\text { (FA) }\end{array}$ & $\begin{array}{c}\mathrm{C}_{16} \mathrm{H}_{10} \\
202\end{array}$ & & Low* & $\begin{array}{l}\text { Dibenz[a,h]- } \\
\text { anthracene } \\
(\mathrm{DaA})\end{array}$ & $\begin{array}{c}\mathrm{C}_{22} \mathrm{H}_{14} \\
278\end{array}$ & & High* \\
\hline $\begin{array}{l}\text { Pyrene } \\
(\mathrm{PY})\end{array}$ & $\begin{array}{c}\mathrm{C}_{16} \mathrm{H}_{10} \\
202\end{array}$ & & Low & $\begin{array}{l}\text { Coronene } \\
(\mathrm{COR})\end{array}$ & $\begin{array}{c}\mathrm{C}_{24} \mathrm{H}_{12} \\
300\end{array}$ & & High \\
\hline $\begin{array}{l}\text { Cyclopenta(CD) } \\
\text { Pyrene (CpPY) }\end{array}$ & $\begin{array}{c}\mathrm{C}_{18} \mathrm{H}_{10} \\
226\end{array}$ & & High & $\begin{array}{l}\text { Dibenzo[a,l] } \\
\text { pyrene } \\
(\text { DBP-al) }\end{array}$ & $\begin{array}{c}\mathrm{C}_{24} \mathrm{H}_{14} \\
302\end{array}$ & & $\operatorname{High}^{\dagger}$ \\
\hline $\begin{array}{l}\text { Benz[a]anthracene } \\
(\mathrm{BaA})\end{array}$ & $\begin{array}{c}\mathrm{C}_{18} \mathrm{H}_{12} \\
228\end{array}$ & & High & $\begin{array}{l}\text { Dibenzo[a,e] } \\
\text { pyrene } \\
(\mathrm{DBP}-\mathrm{ae})\end{array}$ & $\begin{array}{c}\mathrm{C}_{24} \mathrm{H}_{14} \\
302\end{array}$ & & $\operatorname{High}^{\dagger}$ \\
\hline $\begin{array}{l}\text { Chrysene } \\
\text { (CHR) }\end{array}$ & $\begin{array}{c}\mathrm{C}_{18} \mathrm{H}_{12} \\
228\end{array}$ & & High & $\begin{array}{l}\text { Dibenzo[a,i] } \\
\text { pyrene } \\
\text { (DBP-ai) }\end{array}$ & $\begin{array}{c}\mathrm{C}_{24} \mathrm{H}_{14} \\
302\end{array}$ & & $\mathrm{High}^{\dagger}$ \\
\hline $\begin{array}{l}\text { 5-Methyl } \\
\text { Chrysene } \\
\text { (5M-CHR) }\end{array}$ & $\begin{array}{c}\mathrm{C}_{19} \mathrm{H}_{14} \\
242\end{array}$ & & High* & $\begin{array}{l}\text { Dibenzo[a,l] } \\
\text { pyrene } \\
(\text { DBP-al) }\end{array}$ & $\begin{array}{c}\mathrm{C}_{24} \mathrm{H}_{14} \\
302\end{array}$ & & $\operatorname{High}^{\dagger}$ \\
\hline
\end{tabular}

*Excluded from PCA-MLR analysis due to infrequent detection in GCMS

"Isomers co-eluted so quantified as a group in GCMS

${ }^{\dagger}$ Isomers lumped together for analysis, quantified by GCMS separately

Figure S5: PAHs used for GCMS analysis. PAHs having infrequent detection were excluded, and a few PAHs were lumped together for PCA-MLR analysis in which 16 PAHs are considered. Deuterium labeled analogs of the compounds shown in bold were used as internal standards. 
Calibration standards were prepared for the 24 compounds listed in Figure S5. Twenty-three of the native compounds were provided as a mixture (Wellington Laboratories Cat. \# PAH-STK-A, Guelph, ON, Canada), and Coronene was added as an additional analyte (AccuStandard Cat. \# H116, New Haven, CT, USA). Sixteen deuterium-labeled internal standard compounds (shown in bold in Figure S5) were provided in a mixture (Wellington Laboratories Cat. \# PAH-LCS-A, Guelph, ON, Canada). These internal standard compounds were included in each calibrant and spiked into each sample at a constant concentration of $100 \mathrm{ng} / \mathrm{mL}$. For compounds without a deuterium-labeled analogue, we used the deuterium labelled compound with the closest molecular weight as an internal standard. Our calibration curve consisted of the following concentration levels: 1, 4, 10, 40, 100, 400, and $1000 \mathrm{ng} / \mathrm{mL}$.

\section{Argon Dilution of Fuel}

\begin{tabular}{|c|c|c|c|c|c|}
\hline $\begin{array}{c}T_{\text {max }}=1697 \\
\text { Ar Dil =90\% }\end{array}$ & $\begin{array}{c}T_{\max }=1791 \\
\text { Ar Dil =85\% }\end{array}$ & $\begin{array}{c}T_{\max }=1834 \\
\text { Ar Dil =80\% }\end{array}$ & $\begin{array}{c}T_{\max }=1896 \\
\text { Ar Dil }=67 \%\end{array}$ & $\begin{array}{c}T_{\max }=1921 \\
\text { Ar Dil }=50 \%\end{array}$ & $\begin{array}{c}T_{\max }=1966 \\
\text { Ar Dil }=0 \%\end{array}$ \\
\hline & & & &
\end{tabular}

Figure S6: Ethylene flame brightness variation with $T_{\max }$ and argon dilution (Ar Dil), image exposure is varied.

\begin{tabular}{|c|c|c|c|c|c|c|}
\hline $\begin{array}{l}T_{\text {max }}=1734 \\
\text { Ar Dil }=85 \%\end{array}$ & $\begin{array}{l}T_{\max }=1784 \\
A_{r} \text { Dil }=80 \%\end{array}$ & $T_{\max }=1856$ & $\begin{array}{l}T_{\max }=1885 \\
\text { Ar Dil }=60 \%\end{array}$ & $\begin{array}{l}T_{\text {max }}=1914 \\
\text { Ar Dil }=50 \%\end{array}$ & $\begin{array}{l}T_{\text {max }}=1944 \\
\text { Ar Dil }=25 \%\end{array}$ & $\begin{array}{c}T_{\max }=1949 \\
\text { Ar Dil }=0 \%\end{array}$ \\
\hline 1 & & & 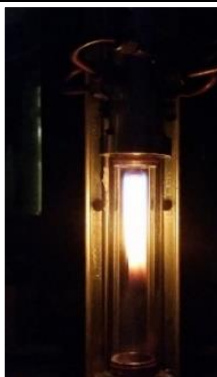 & 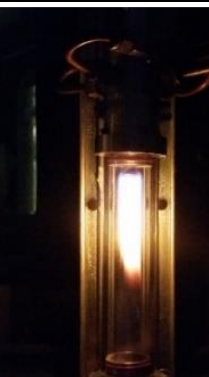 & 1 & int. \\
\hline
\end{tabular}

Figure S7: Ethane flame brightness variation with $T_{\max }$ and argon dilution (Ar Dil), image exposure is varied. 

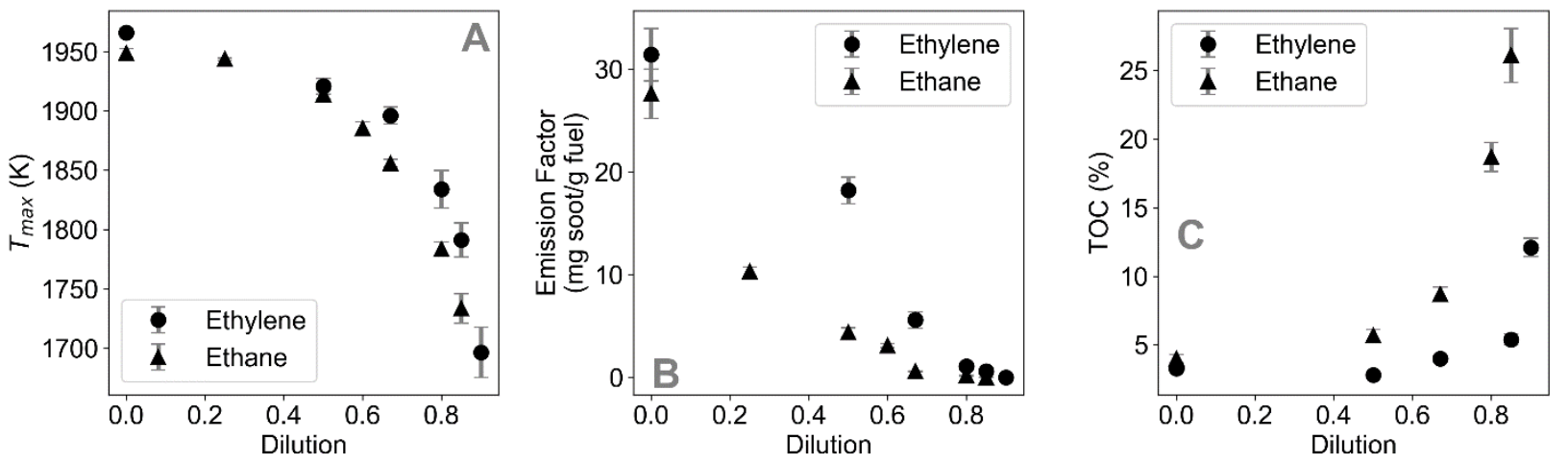

Figure S8: Argon dilution affects the maximum flame temperature $\left(T_{\max }\right)$, soot emission factor and TOC from ethylene and ethane flames. (A): The maximum flame temperature decreases for higher Ar dilution for both fuels. (B): The emission factor (soot yields) decreases with argon dilution. (C): TOC fraction increases with argon dilution.

\section{Gas Chromatography Mass Spectroscopy}



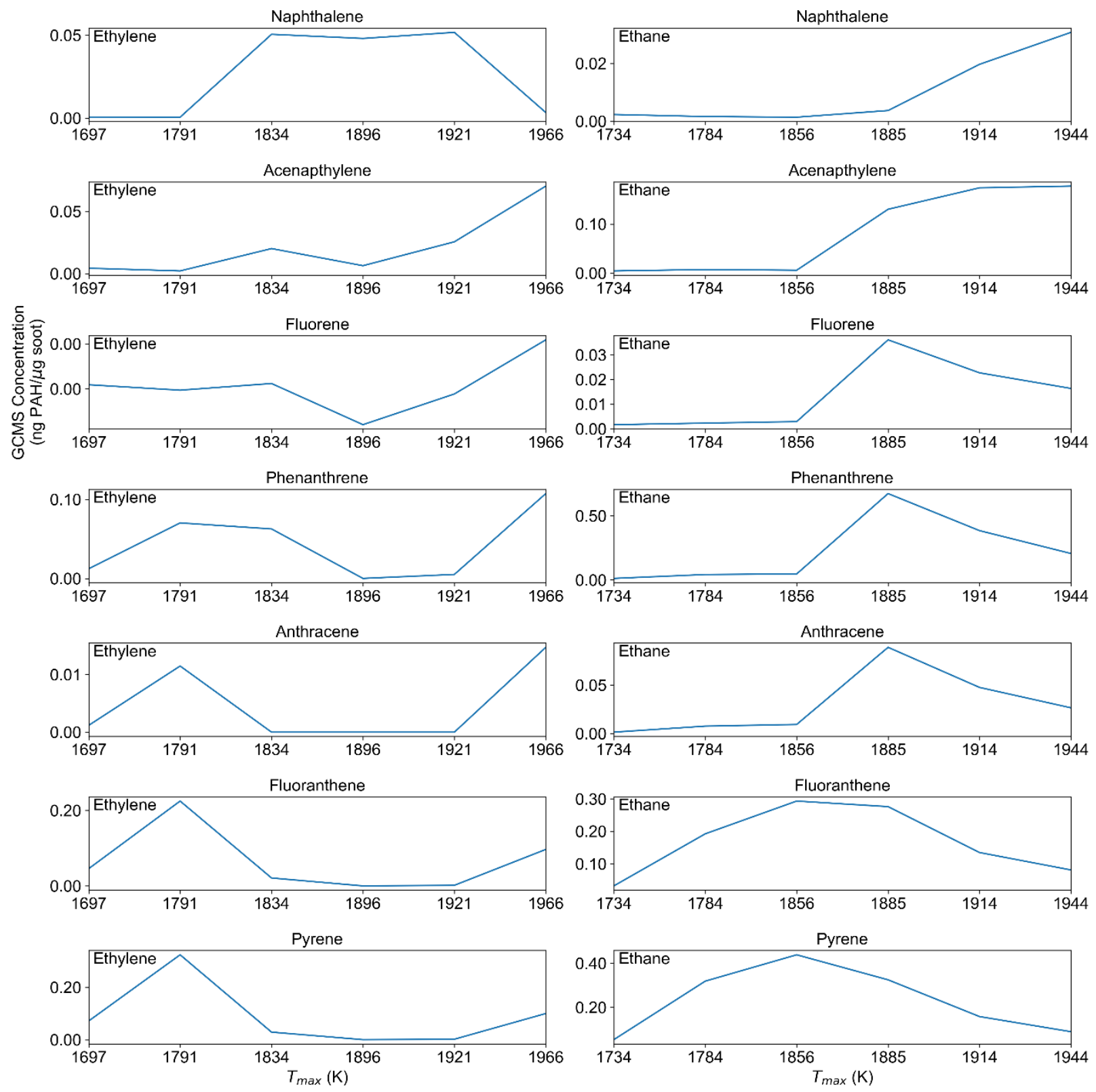

Figure S9: Variation of GCMS concentration of each of the LMW PAHs vs. $T_{\max }$ for ethylene and ethane fuels. 

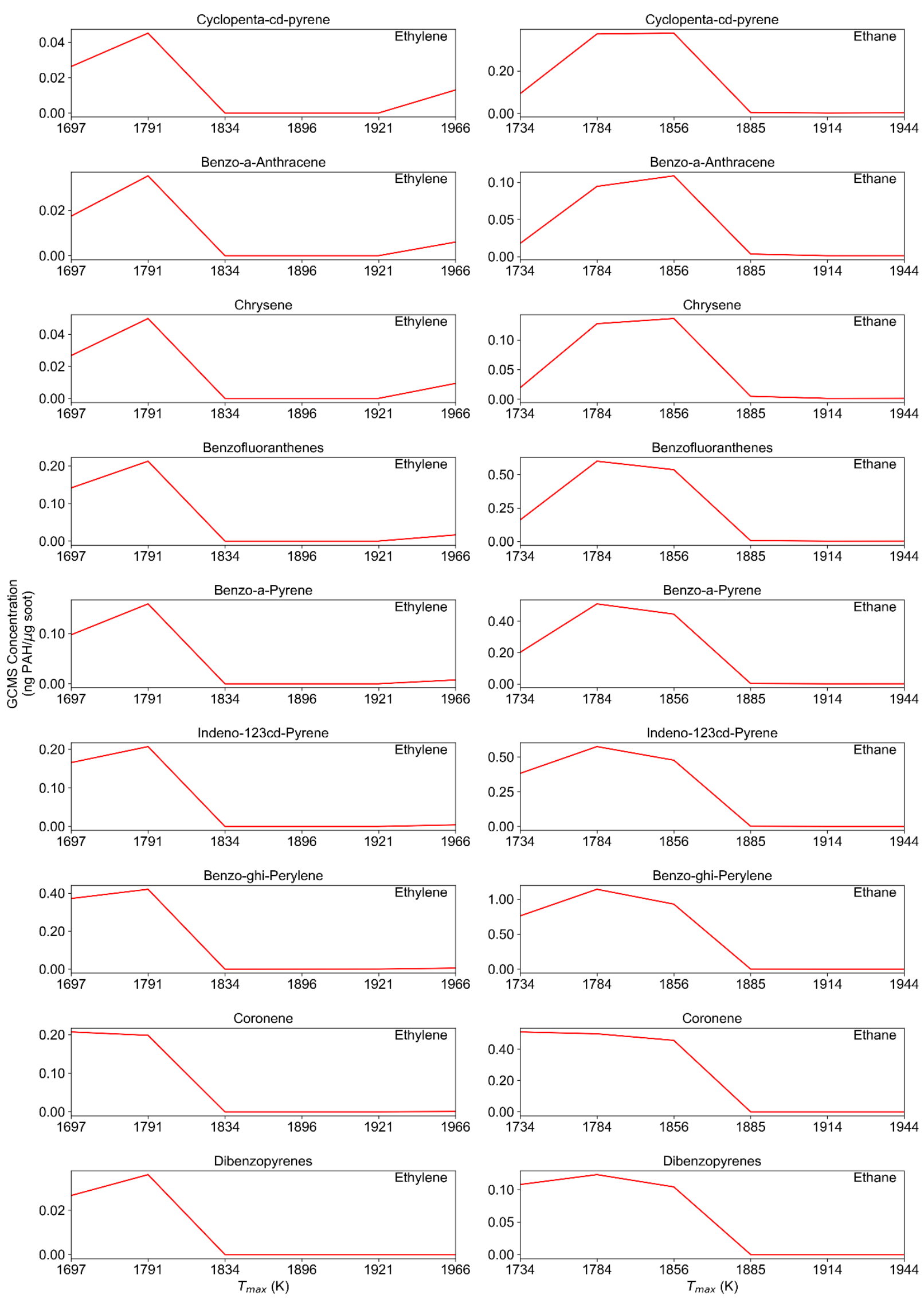
Figure S10: Variation in GCMS concentration of each of the HMW PAHs with varying $T_{\max }$ for both fuels. The HMW PAH concentration increases for low temperatures.

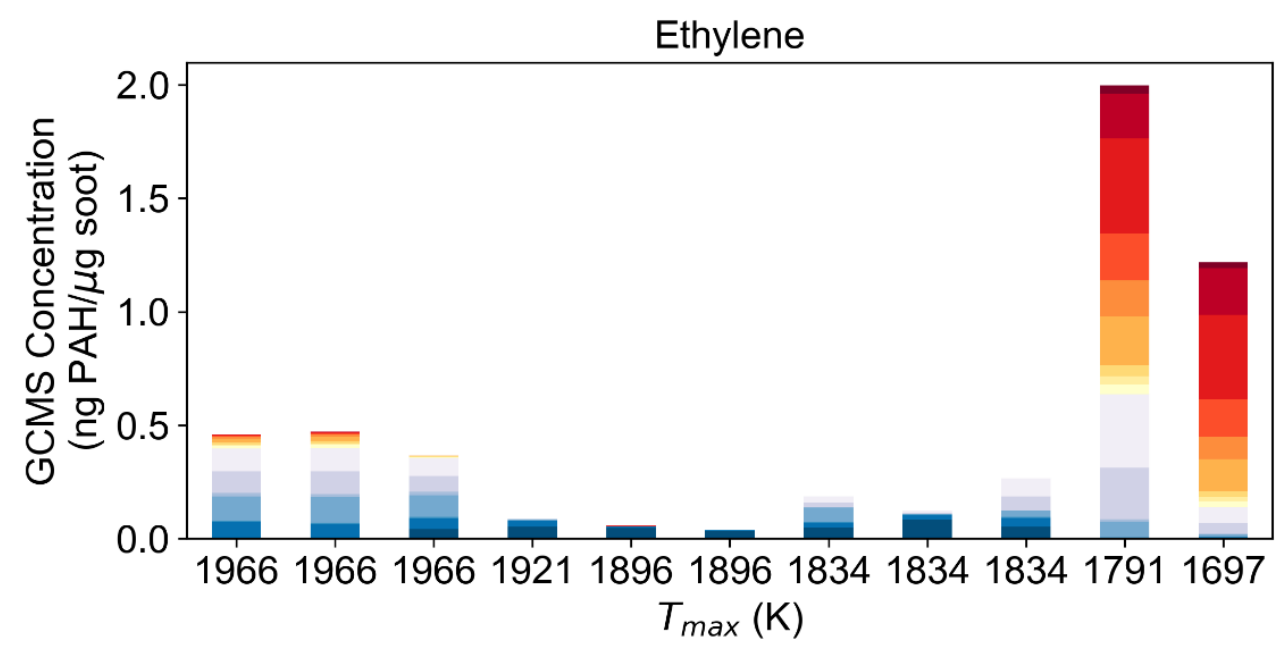 High Molecular Weight PAHs (MW $226-302 \mathrm{~g} / \mathrm{mol}$ )
Dibenzopyrenes
- Coronene
Benzo-ghi-Perylene
Indeno-123cd-Pyrene
Benzo-a-Pyrene
Benzofluoranthenes
Chrysene
Benzo-a-Anthracene
Cyclopenta-cd-pyrene
Low Molecular Weight PAHs
(MW 128 - $202 \mathrm{~g} / \mathrm{mol}$ )
Pyrene
Fluoranthene
Anthracene
- Phenanthrene
- Fluorene
Acenapthylene
- Naphthalene

Figure S11: GCMS concentration of PAHs of three different ethylene soot samples having the same $T_{\max }$ are similar. 


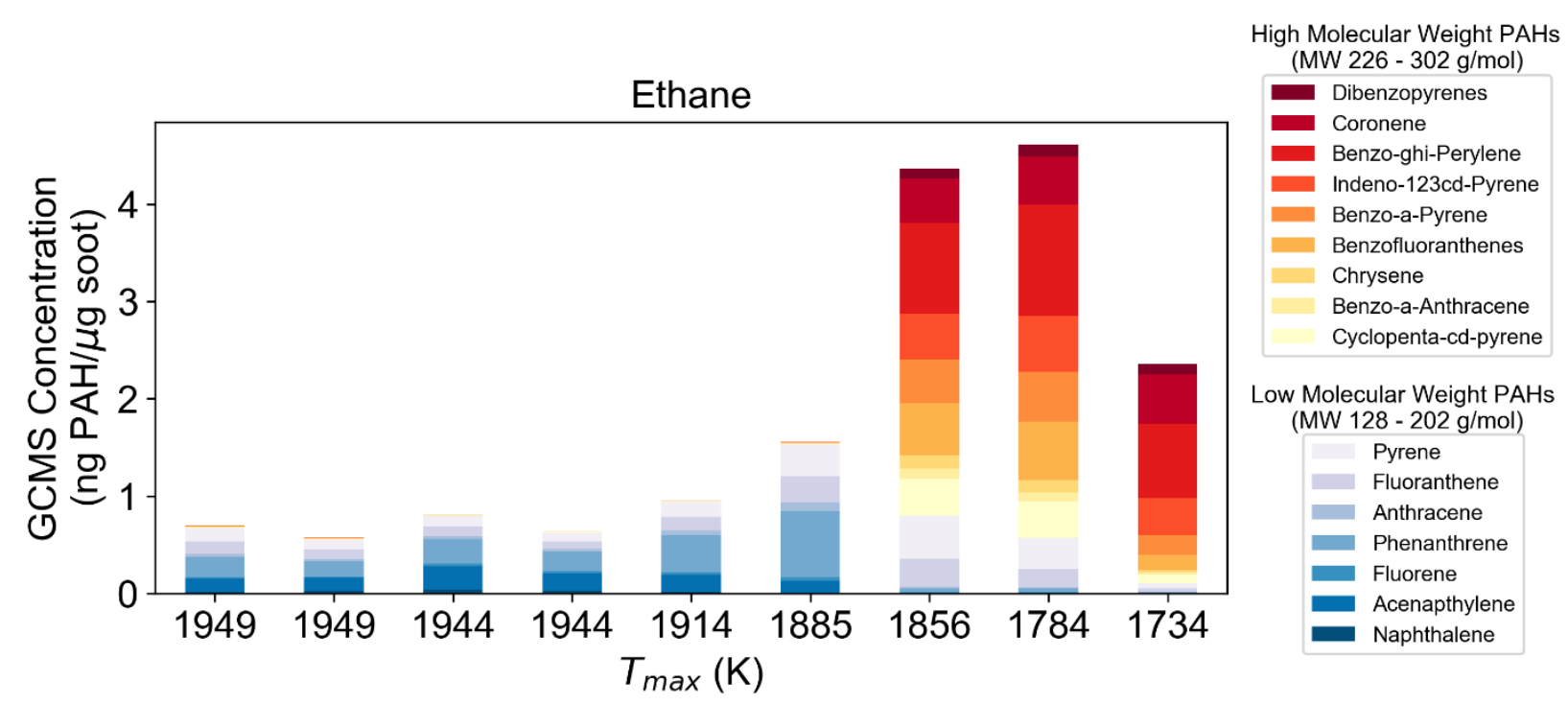

Figure S12: GCMS concentration of PAHs of three different ethane soot samples having the same $T_{\max }$ are similar. 


\section{Excitation Emission Matrix (EEM)}
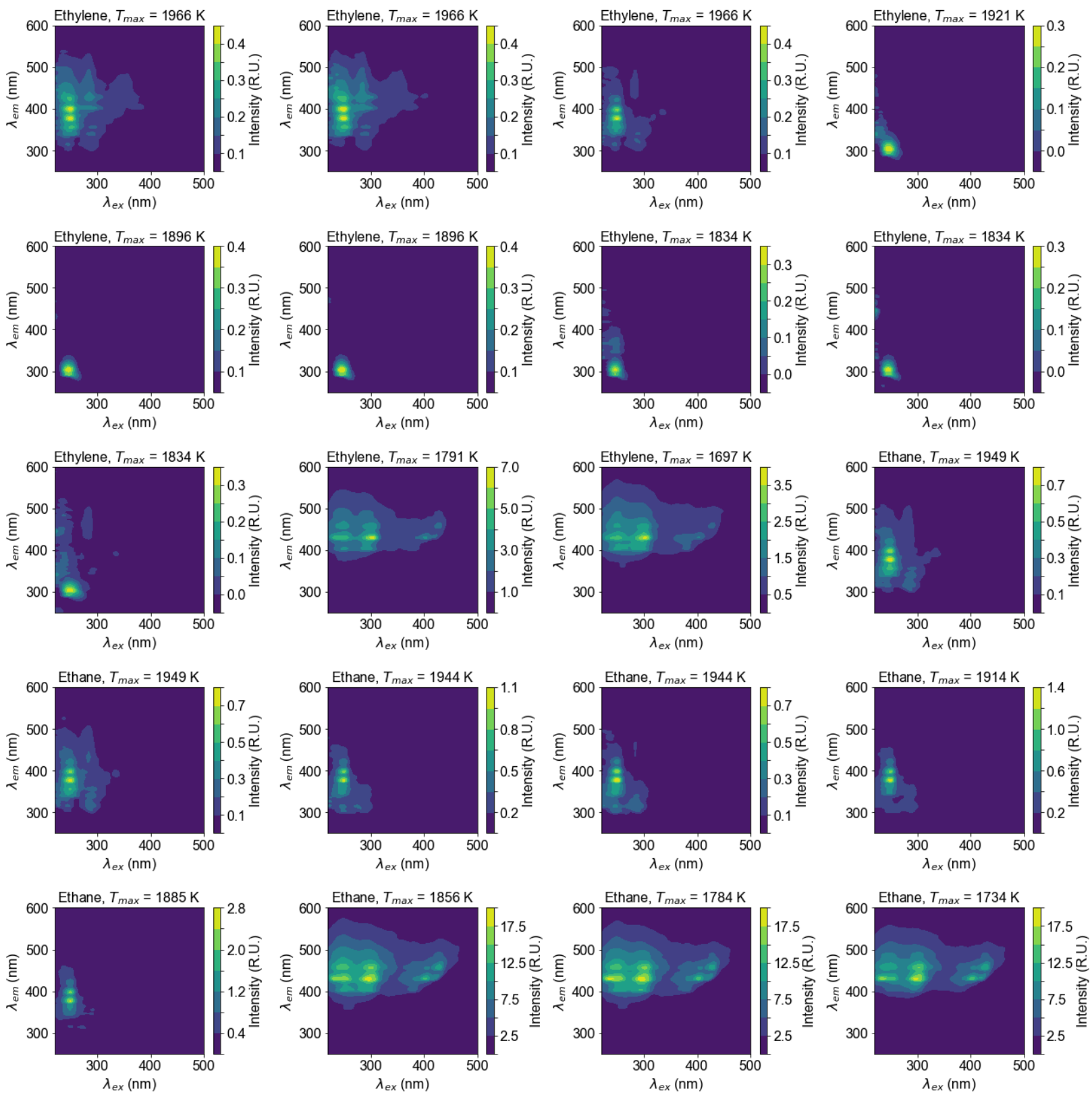

Figure S13: EEM spectra of PM from the combustion of ethylene and ethane fuels in the entire range of $T_{\max }$ considered in this study. 

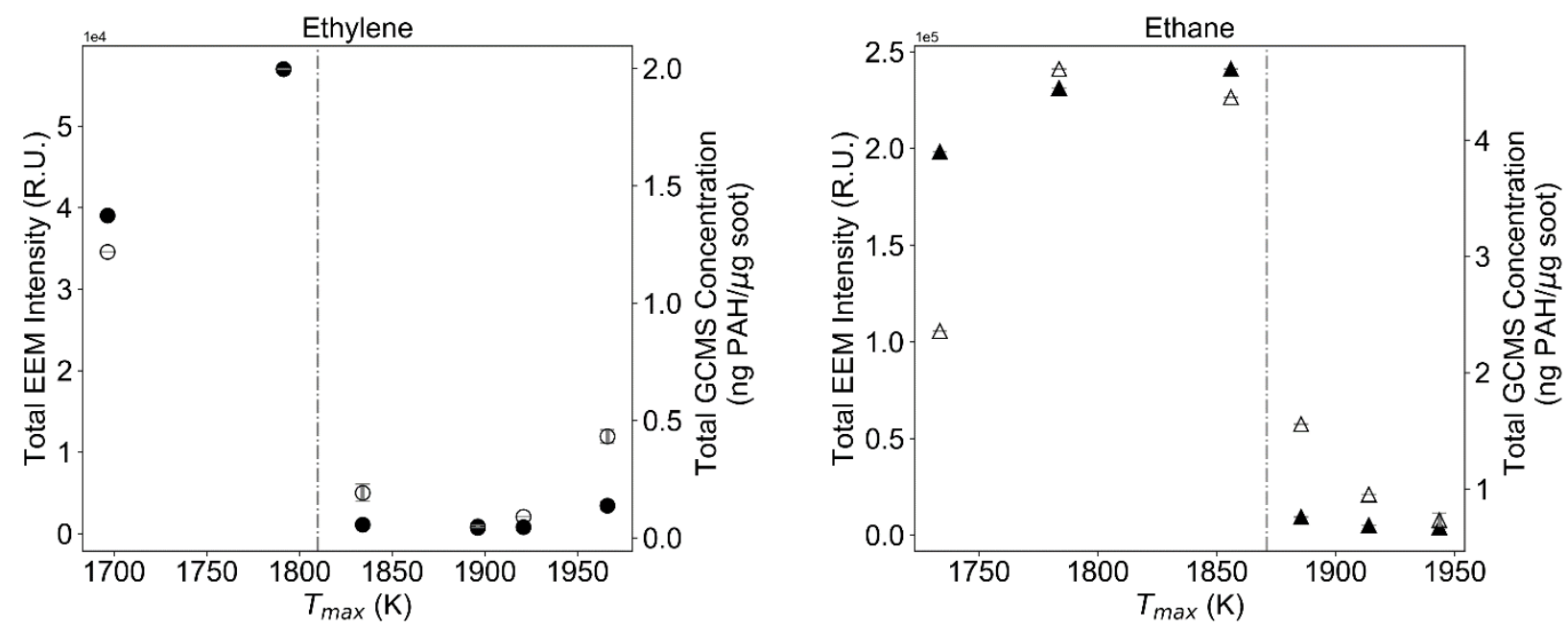

$\Phi$ T Total GCMS Concentration $\mathbf{\Phi}$ ㅍ Total EEM Intensity

Figure S14: Comparison of total EEM fluorescence to PAH concentration from GCMS analysis of 24 PAHs panel for PM from diluted IGFR ethylene and ethane flames. The error bars are plotted using standard deviation when multiple samples are used. The plot shows that there is very little variation in samples collected at the same conditions.
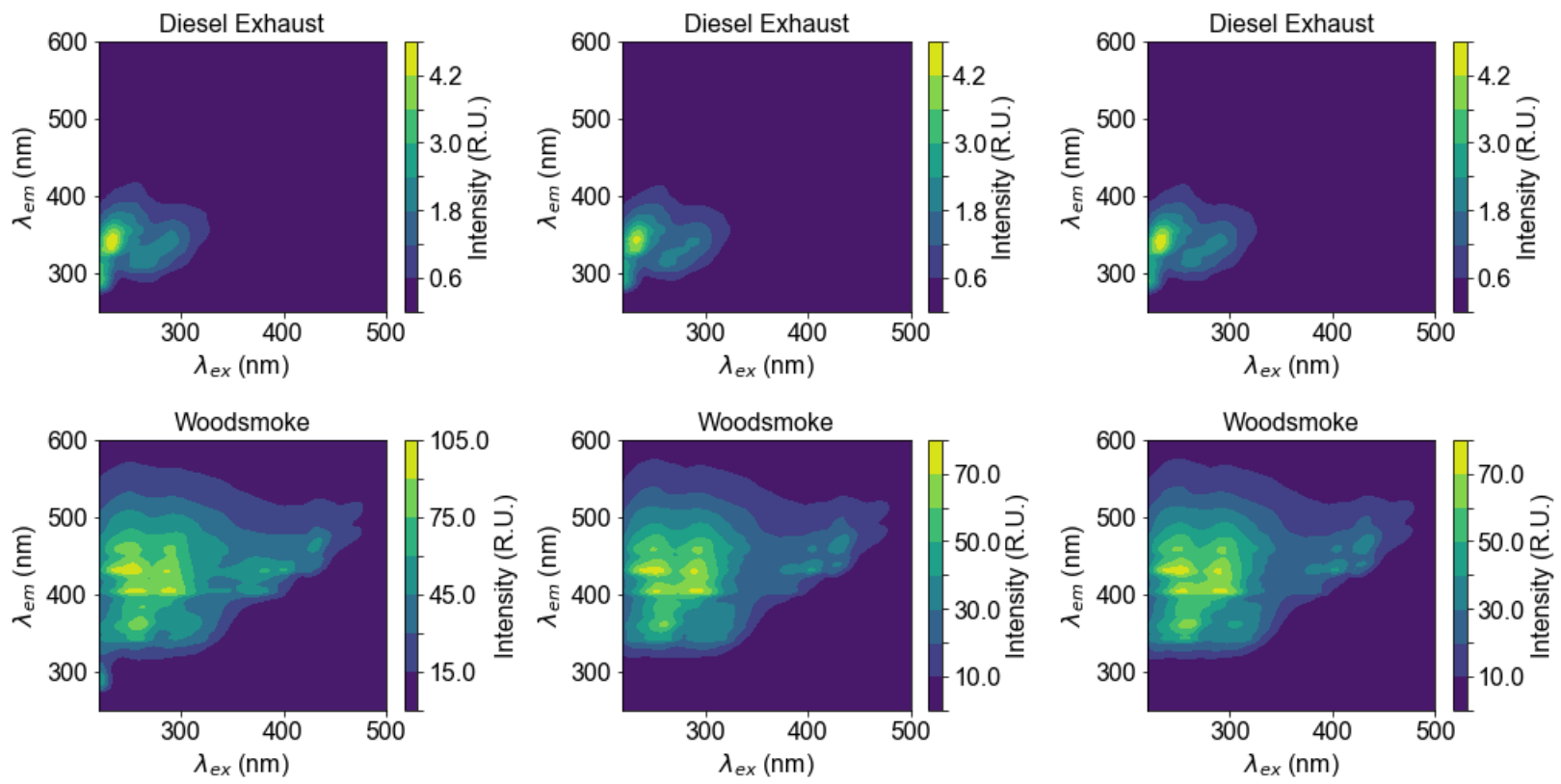

Figure S15: EEMs of three different samples of the same source have similar peaks for diesel exhaust and woodsmoke. 

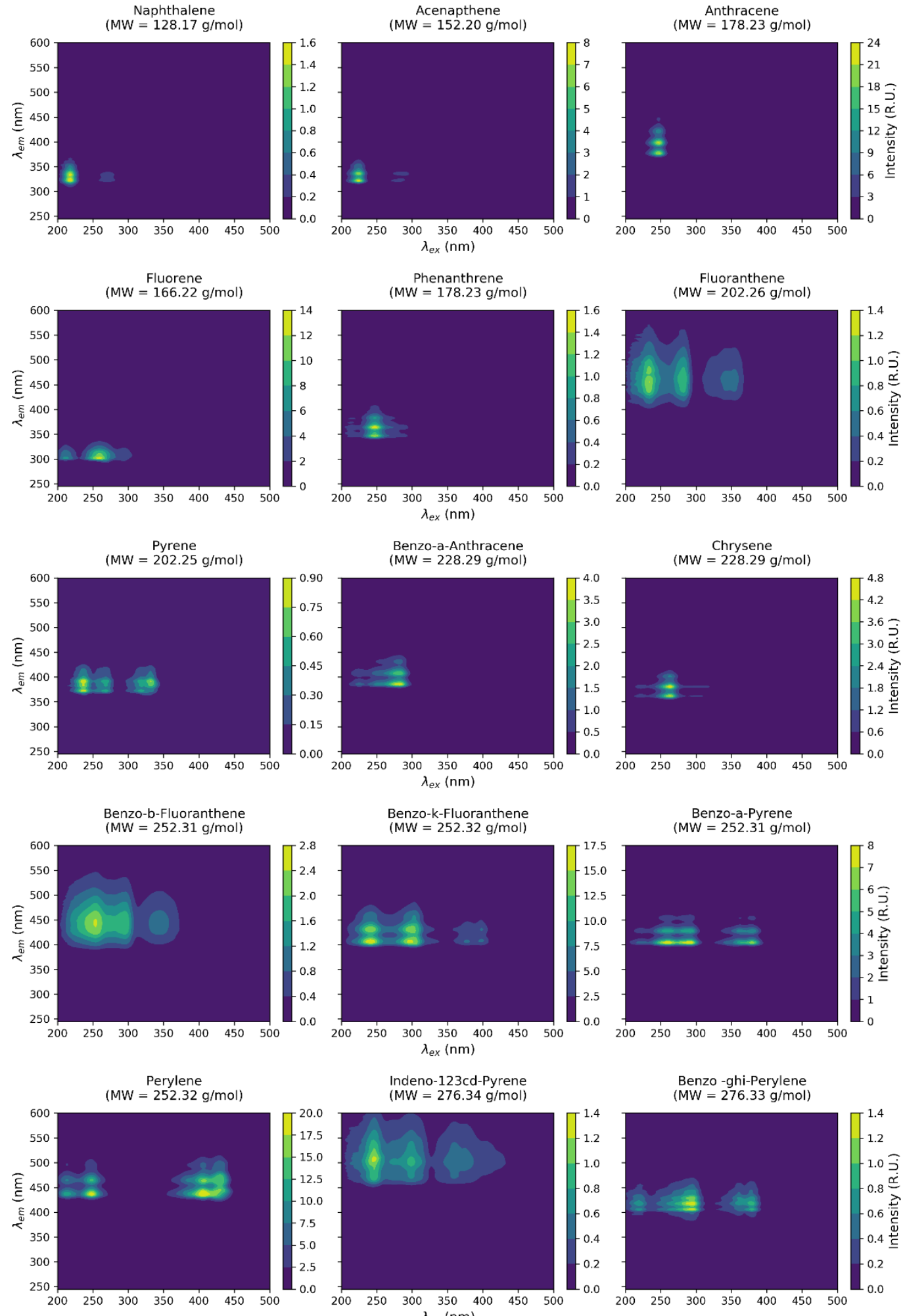

Indeno-123cd-Pyrene $(\mathrm{MW}=276.34 \mathrm{~g} / \mathrm{mol})$

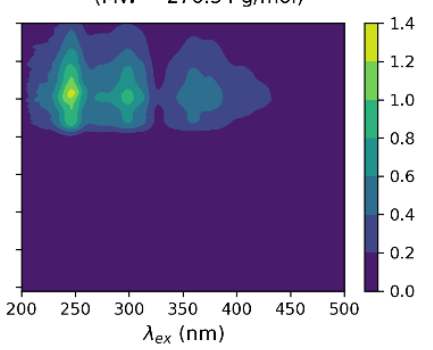

Benzo -ghi-Perylene ( $\mathrm{MW}=276.33 \mathrm{~g} / \mathrm{mol}$ )

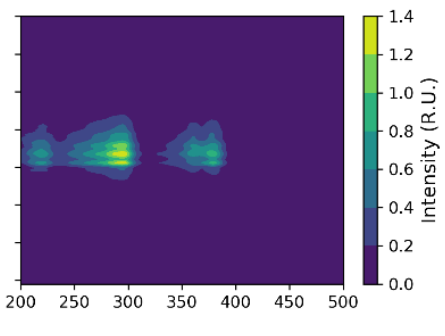

Figure S16: EEM spectra of 15 of the 24 PAHs analyzed using GCMS. 


\section{Principal Component Regression}
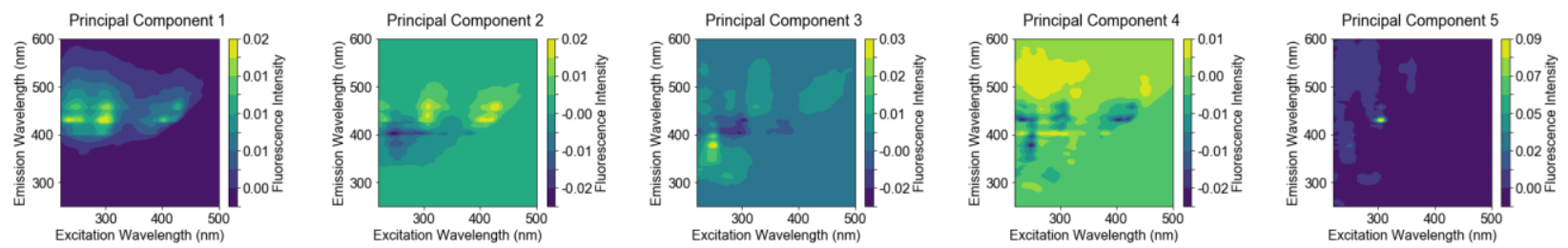

Figure S17: Principal Components of the EEM data are non-interpretable. The first five principal components account for $99.99 \%$ variance in data.

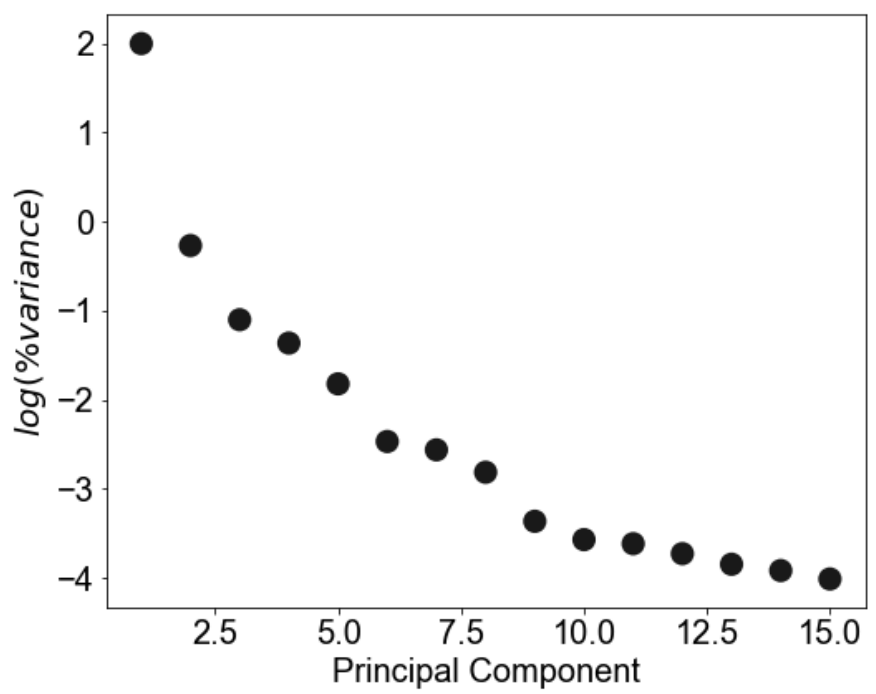

Figure S18: Contribution of each PC to the total variance of the EEM dataset is represented in terms of $\log (\%$ variance $)$. 

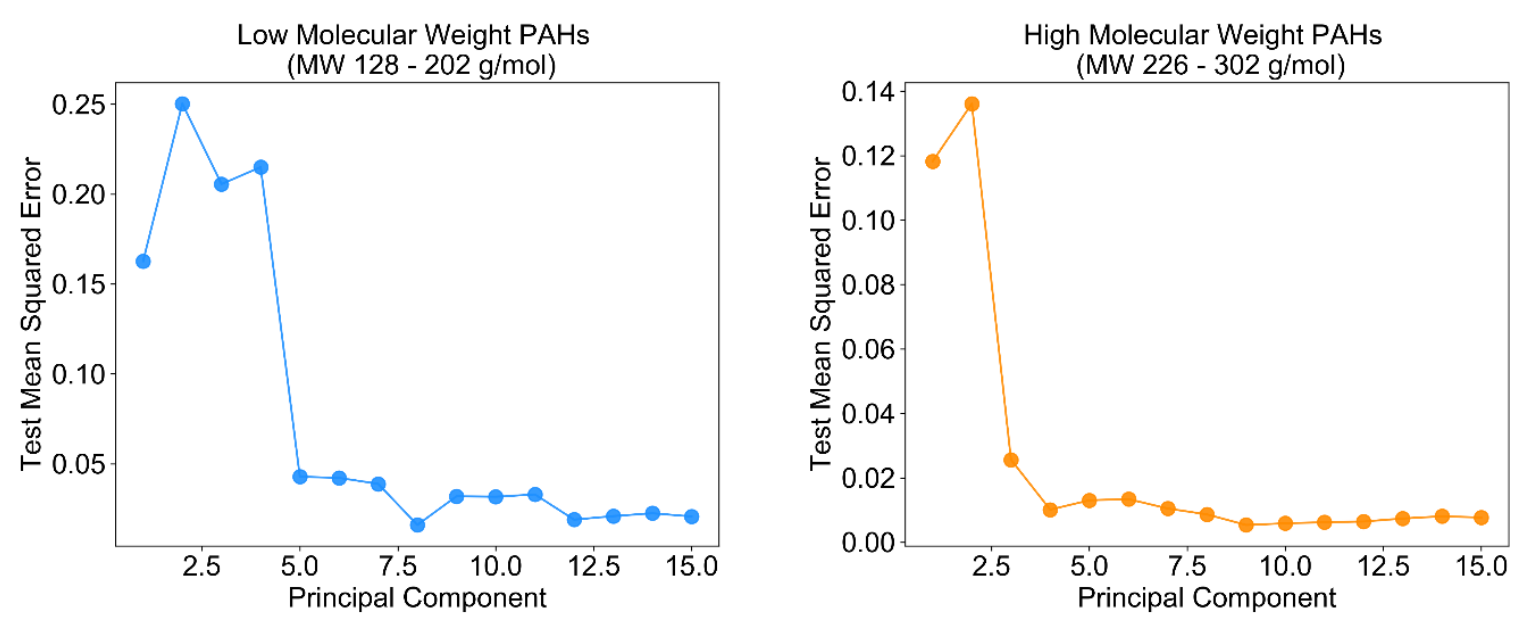

Figure S19: Mean Squared Error (MSE) calculated using leave one out cross-validation (LOOCV) for different number of PCs for LMW and HMW PAHs.

\section{PM Matrix Effects}

In this section, we explore the performance of the PCR-EEM method for PM matrix effects. We consider two situations: 1. PM is from a mixture of real-world sources 2. PM is aged.

To evaluate the PCR-EEM method with PM mixtures, we perform computational mixing of EEM data and corresponding GCMS concentration of PAHs to generate 16 new samples from the six diesel-exhaust and woodsmoke samples used for testing the PCR-EEM method in the main manuscript. During each iteration of generating the 16 new samples, three samples were picked randomly from the six original test samples, their EEM data and PAH concentrations were multiplied by a constant value between $2 / 15$ and 8/15 (1/3 $\pm 1 / 5)$ and added to generate a new EEM and its corresponding PAH concentration profile. The EEM generated by computational mixing is similar to the EEM recorded from physically mixed PM samples. ${ }^{9}$ GCMS concentration of PAHs can be computationally mixed to generate new PAH profiles as PAH fluorescence intensity vary linearly with their concentration. ${ }^{10}$

The computationally mixed 16 new samples were created and added to the original six test samples to create a new test dataset having 22 samples. The PCR-EEM models for LMW and HMW PAH concentration estimation, developed using IGFR samples, were tested using the new test dataset. The results in Figure $\mathrm{S} 20$ show that the $\mathrm{R}^{2}$ for estimating HMW PAH concentrations is 0.973 while the LMW PAH concentrations are overestimated. These correlations are similar to the ones when the original test dataset with 6 samples was used. Hence, PM mixing does not affect the PCR-EEM estimates. 

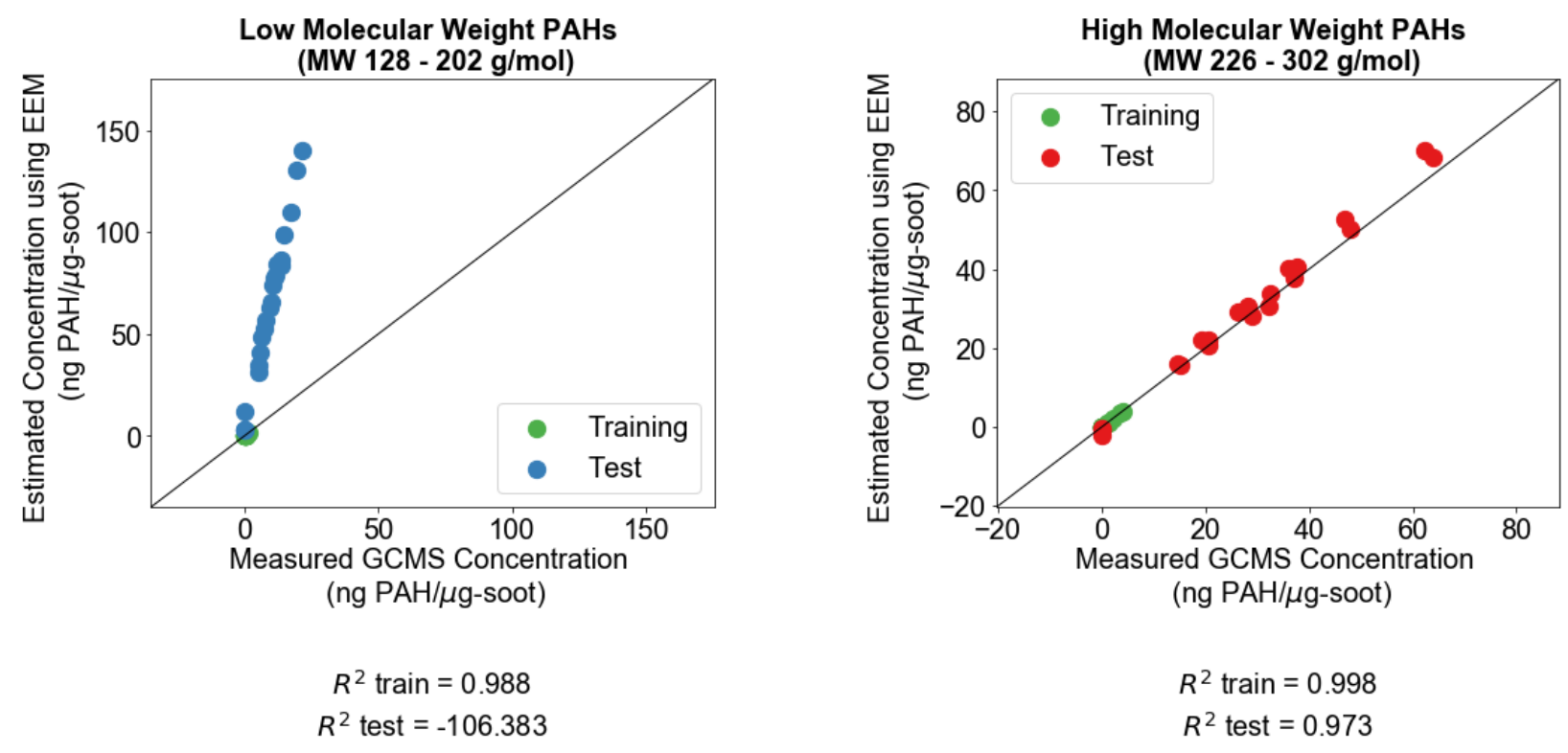

Figure S20: Parity plots of PAH concentrations estimated by PCR-EEM vs. concentration measured by GCMS for LMW (left) and HMW (right) PAHs in PM samples from ethylene and ethane flames (training), an original and computationally created woodsmoke and diesel exhaust (test). PM mixing does not affect PCR-EEM method performance.

Lower molecular weight compounds are overpredicted if training data include only the IGFR samples. Though we no do have full insight explaining the discrepancy, the more volatile compounds are significantly affected during sample collection, and photodegradation also changes PAH composition in young vs. aged soot. ${ }^{11}$ Perhaps the greatest uncertainty is the presence of the fluorescent non-PAH species in these combustion sources. The route to PM formation for gaseous, liquid and solid fuel is likely to influence the composition organic carbon fraction. While simple gaseous fuels were used in the training set, diesel exhaust and the biomass combustion are significantly more complex. The initial fuel pyrolysis step produces a great variety of the C-H compounds that are not present in simple flames. ${ }^{12} \mathrm{We}$ also found that high molecular weight compounds in PM are more stable (fluorescent signature of the extract does not change) during sample collection. The prediction of the HMW compounds over combustion source tested is in excellent agreement with the original training set, see Fig S20.

Although PM aging effects on PAH composition is not part of the study, in a pilot experiment, we compare EEMs of young and aged diesel exhaust. Diesel PM was generated by a $435 \mathrm{cc}$ directinjection single-cylinder diesel engine (Yanmar LW Series) operated on ultra-low-sulfur diesel. Young diesel exhaust PM was collected from an exhaust duct connecting the diesel engine exhaust to the exposure room at the University of Washington's controlled inhalation diesel exhaust exposure facility by sampling devices placed in a sealed chamber. ${ }^{13}$ Aged diesel exhaust PM was 
collected in the exposure room. ${ }^{9}$ Note that the aged exhaust was not exposed to long term solar radiation or temperature change, and was not mixed with other sources. Although PM aging occurs for only a few minutes, there is a change in PM concentration and environmental exposure between young and aged PM.

Figure S21 shows EEMs of young and aged diesel exhaust. The fluorescent peak with the highest intensity is in the same location for both samples; however, other fluorescent regions have slightly different features. Also, maximum fluorescence intensity for the aged sample is less than the young sample (The samples are concentration normalized). This might be reflective of loss in PAHs during aging. This suggests that EEM measurements might be capable of showing aging effects and that the PCR-EEM method can provide an accurate estimation of HMW PAH concentrations for young as well as aged PM samples.
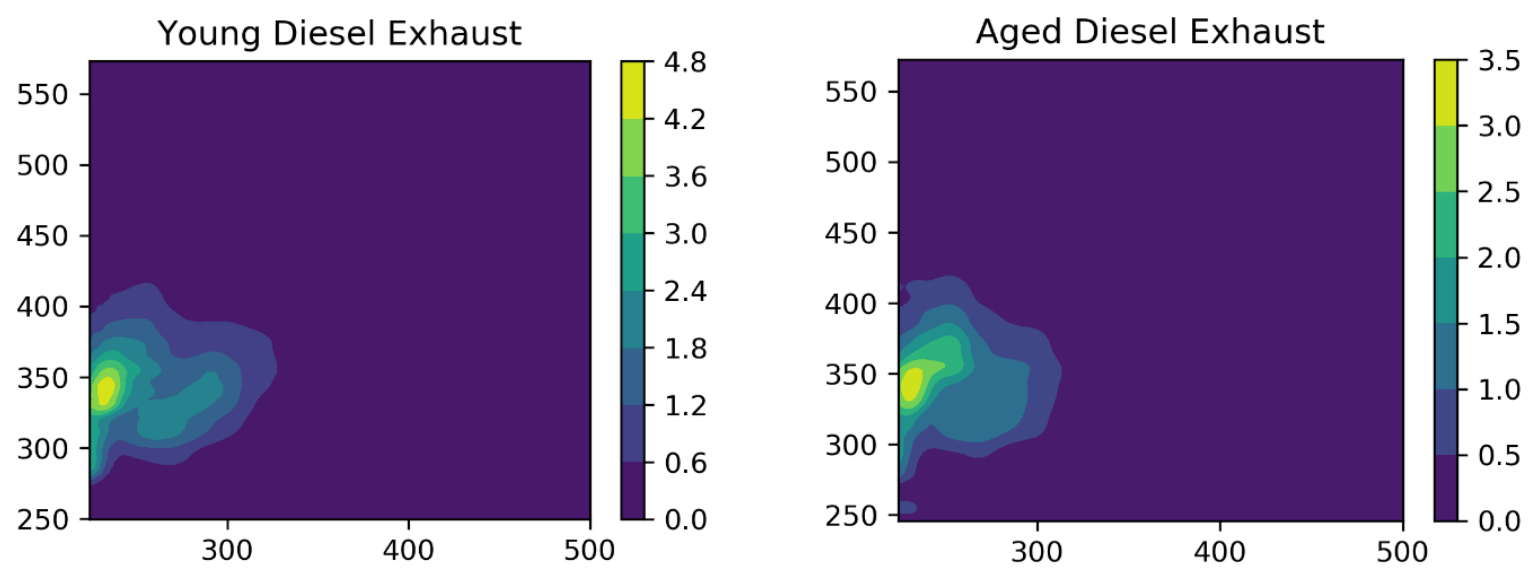

Figure S21: EEMs of young vs. aged PM diesel exhaust have slightly different fluorescent peaks and intensities which might be reflective PAH loss due to aging

\section{Estimating HMW PAH concentrations for single PAHs using PCR-EEM method}

\subsection{Experimental Methods}

\subsubsection{Creating EEMs}

The training dataset consists of IGFR samples, which has 20 EEM matrices of size 1000 X 201 and their corresponding HMW PAH concentrations. The test dataset consists of woodsmoke and diesel exhaust samples which have 6 EEM image matrices of size 1000 X 201 and their corresponding HMW PAH concentrations. We reduce the size of the EEMs to $100 \mathrm{X} 33$ using 2D MaxPool in Python with filter size $(10,6)$.

To generate more data for training and testing of the PCR model, we compute linear combinations of the existing EEMs and their known HMW PAH concentrations. 580 EEMs were generated from 
the training set and 144 from the test set. Each generated EEM is a linear combination of three randomly chosen EEMs from its respective set with each chosen EEM matrix is multiplied by a random number between $2 / 15$ and 8/15 (1/3 $\pm 1 / 5)$. The EEM spectra generated by computational mixing is similar to the EEM recorded from physically mixed PM samples. ${ }^{9}$ GCMS concentration of PAHs can be computationally mixed to generate new PAH profiles as PAH concentrations vary linearly with fluorescence intensity of PAHs. ${ }^{10}$

\subsubsection{Principal Component Regression (PCR)}

Each EEM in the training set is unfolded as a row array and stacked to create an $\mathrm{n} x \mathrm{p}$ matrix where $\mathrm{n}$ is the number of training samples $(n=600)$ and $\mathrm{p}$ is the number of pixels $(\mathrm{p}=3300)$. The resultant data matrix is demeaned column-wise. The 'PCA' function from class 'sklearn.decomposition' is used to decompose the data matrix. It uses the LAPACK implementation of the full SVD or a randomized truncated SVD, depending on the shape of the input data and the number of components to extract. We plot the percentage variance explained by each component vs. the number of components in Figure S22. A score matrix obtained after PCA of EEMs is representative of each EEM. The dimension of the scores for each EEM is 600 which is reduced to d based on Figure S22. The reduced data matrix $n \times d$ represents the training data.
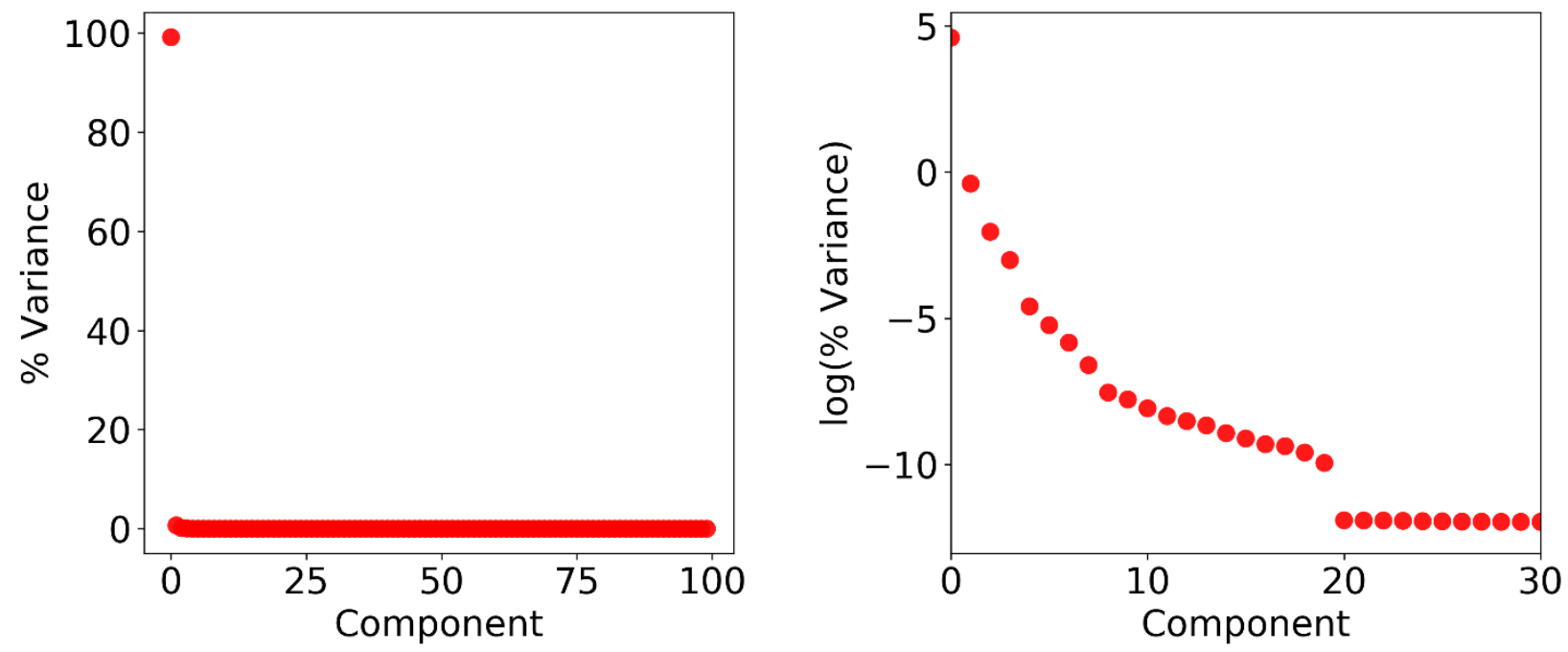

Figure S22: \% Variance for each component (left). Since the first component accounts for most of the variance, a log plot gives more information on the relative contribution of other components to the variance (right).

The 'linear_model' function from class 'sklearn' is used for multiple linear regression analysis. 'LinearRegression' fits a linear model with coefficients to minimize the residual sum of squares between the observed responses in the dataset. We use 'LinearRegression' to compute a linear model between reduced data matrix of size $\mathrm{n} \times \mathrm{d}$ and training labels of size $\mathrm{n} \times 9$ (Concentration of 9 HMW PAHs). The training error is calculated using the linear model. Each EEM in the test set is unfolded and demeaned the same way as EEMs in training set to create a matrix of size $\mathrm{m} \mathrm{x}$ 
$\mathrm{p}$, where $\mathrm{m}(\mathrm{m}=150)$ is the number of test samples. The function 'pca.transform ()$^{\prime}$ ' is used to obtain scores of test samples based on dimensionality reduction of training samples. First, $d$ scores out of 150 scores are chosen. Test PAH concentrations are predicted based on the $\mathrm{d}$ scores for each test sample using the linear model developed using the training set. The test error is calculated.

\subsection{Results and Discussion}

\subsubsection{Performance of Fitted Model to Predict 9 HMW PAH concentrations}

Figure S22 (right) shows that \% variance elbows after 19 components, hence we choose $d=19$. We reduce the dimension of EEMs from 3300 to 19 using PCA. A linear model obtained for scores and HMW PAH concentrations of samples in the training dataset is used to estimate HMW PAH concentrations of samples in the test dataset. The error for estimating HMW PAH concentrations for samples in the test dataset is shown in Figure S23. The \%error is low for Benzofluoranthenes (BFL) and Indeno-123cd-Pyrene (INP) while estimates of other HMW PAH concentrations have higher error.

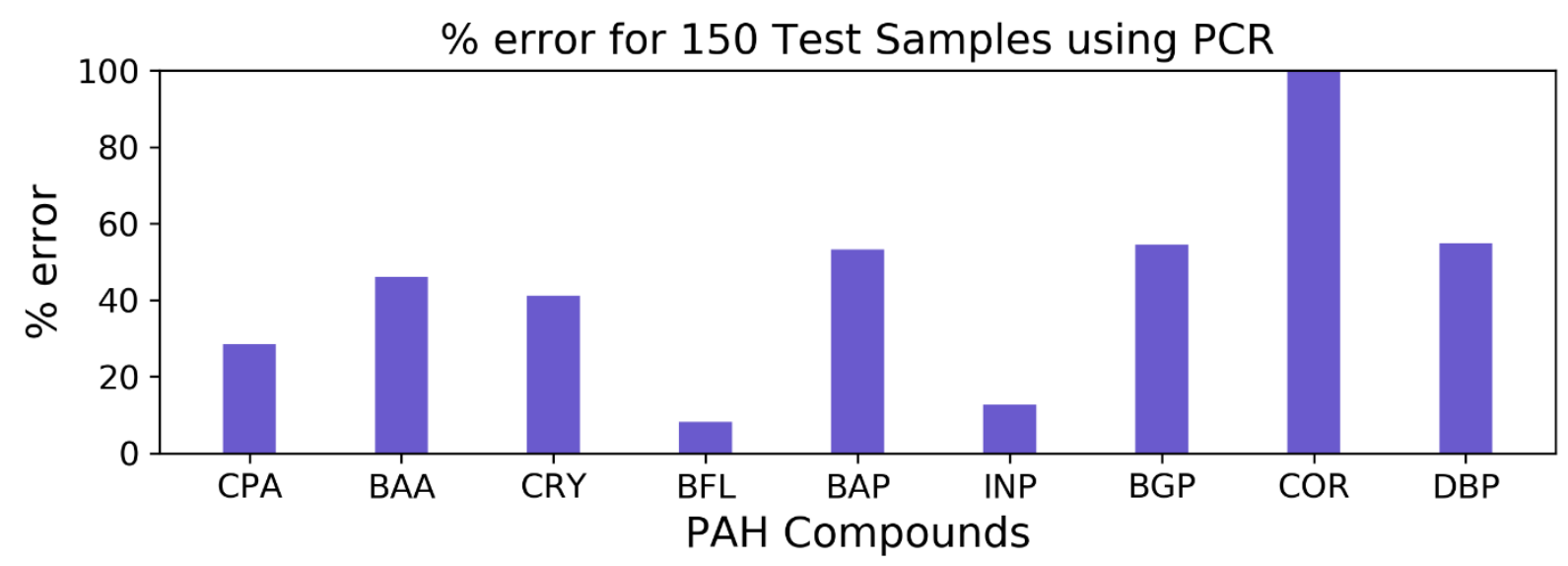

Figure S23: The error for all 9 HMW PAH compounds. The average \%error is $36.6 \%$ 


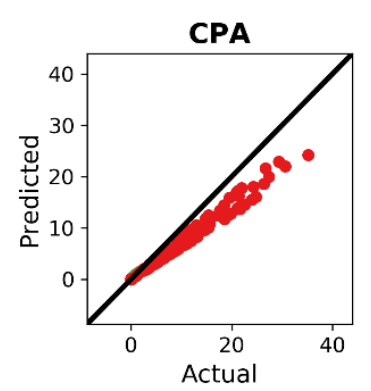

$R^{2}$ train $=1.000$

$R^{2}$ test $=0.773$

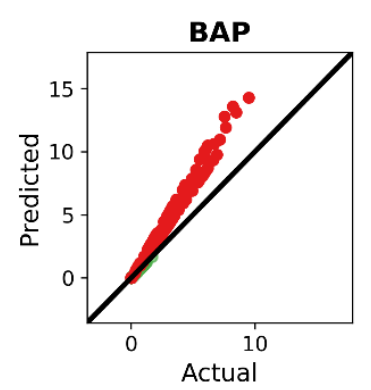

$R^{2}$ train $=1.000$

$R^{2}$ test $=0.188$

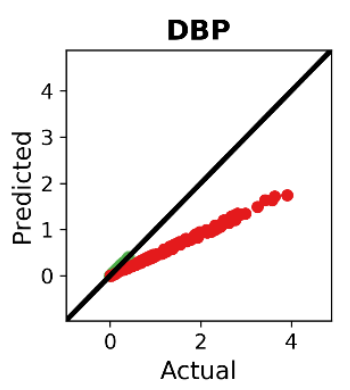

$R^{2}$ train $=1.000$

$R^{2}$ test $=0.198$

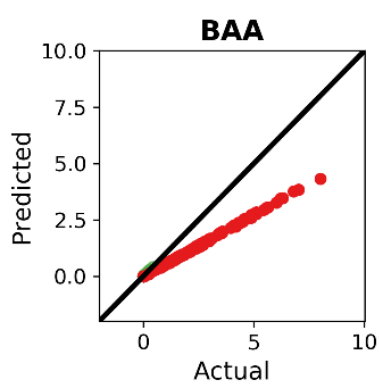

$R^{2}$ train $=1.000$

$R^{2}$ test $=0.443$

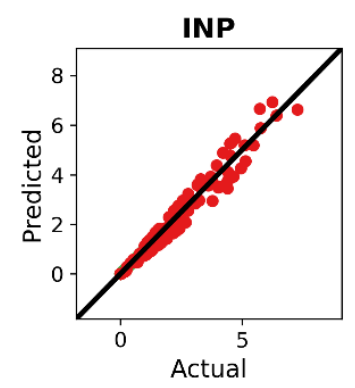

$R^{2}$ train $=1.000$

$R^{2}$ test $=0.955$

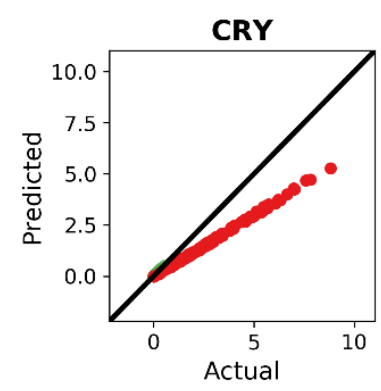

$R^{2}$ train $=1.000$

$R^{2}$ test $=0.563$

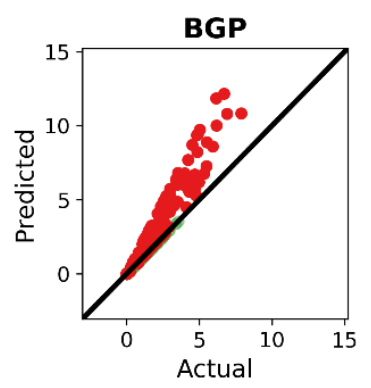

$R^{2}$ train $=1.000$

$R^{2}$ test $=-0.014$

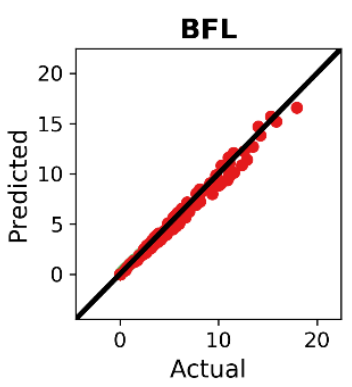

$R^{2}$ train $=1.000$ $R^{2}$ test $=0.980$

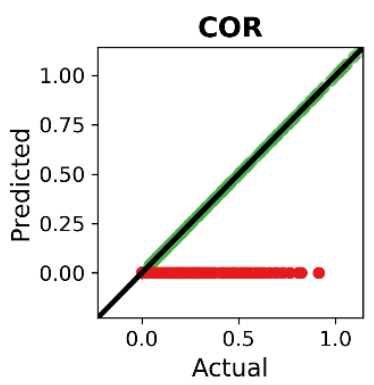

$R^{2}$ train $=1.000$ $R^{2}$ test $=-1.642$

Figure S24: $\mathrm{R}^{2}$ values for training (green) and test (red) for estimating HMW PAH concentration for the individual PAH using the PCR-EEM method. Benzofluoranthenes (BFL) and Indeno123cd-Pyrene (INP) have test $\mathrm{R}^{2}$ close to 1 .

The PCR-EEM method estimates HMW PAH concentrations for single PAHs with reasonable accuracy for only a couple of individual PAHs. Although the relationship between PAH fluorescence intensity and PAH concentration in PM is linear ${ }^{10}$, there are several other fluorescing species in combustion generated PM. The fluorescence spectra of these species overlap. This makes predicting concentration of single PAHs difficult, especially when the number of fluorescent species is high as expected in woodsmoke and diesel exhaust samples due to the complex nature of combustion mechanisms and kinetics for these fuels. The HMW PAH group seems to represent the dominant fluorophores fluorescing at longer wavelengths and broad 
excitation wavelength ranges for samples in the training and test set as the estimates of HMW PAH concentrations are accurate with the PCR model, hence PCR-EEM method is good for estimating concentrations for a group of PAHs but may not be accurate for estimating the concentration of single PAH compounds.

\section{Gaussian Filtering of EEM}
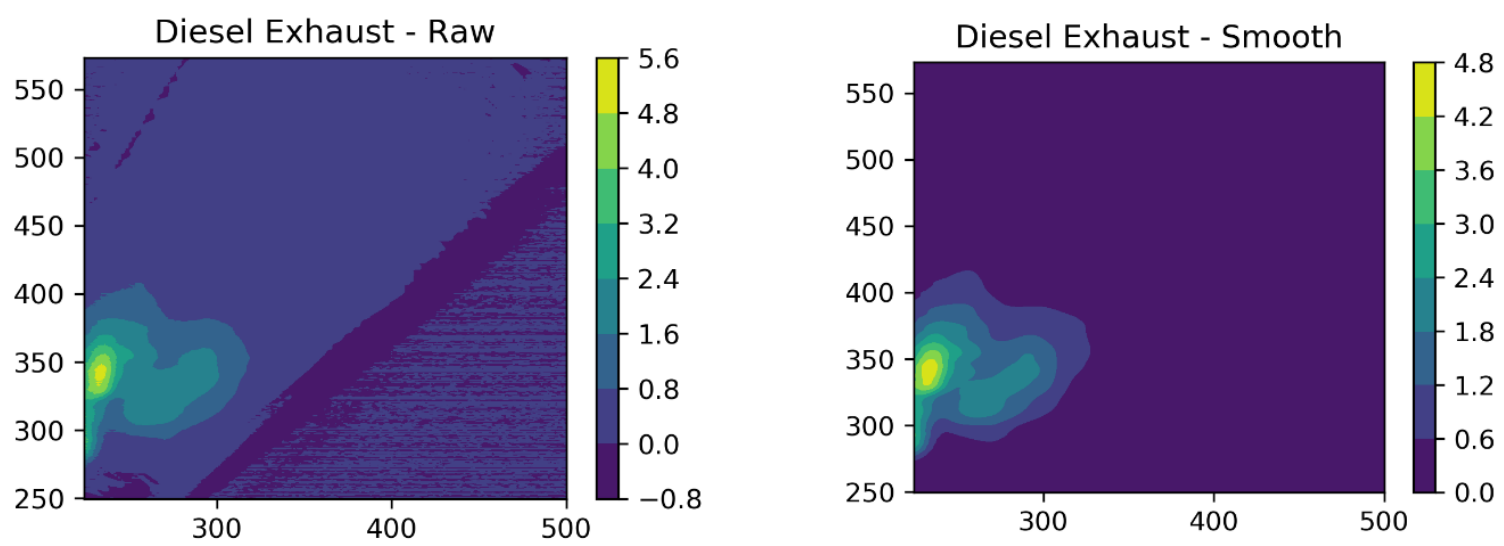

Figure S25: Comparison of raw vs. smooth EEM of diesel exhaust sample after passing through a Gaussian filter and removing negative values.

\section{References}

(1) Shaddix, C. R. Correcting Thermocouple Measurements for Radiation Loss: A Critical Review; CONF-990805-; American Society of Mechanical Engineers, New York, NY (US), 1999.

(2) Kholghy, M. R.; Afarin, Y.; Sediako, A. D.; Barba, J.; Lapuerta, M.; Chu, C.; Weingarten, J.; Borshanpour, B.; Chernov, V.; Thomson, M. J. Comparison of Multiple Diagnostic Techniques to Study Soot Formation and Morphology in a Diffusion Flame. Combust. Flame 2017, 176, 567-583. https://doi.org/10.1016/j.combustflame.2016.11.012.

(3) Hindasageri, V.; Vedula, R. P.; Prabhu, S. V. Thermocouple Error Correction for Measuring the Flame Temperature with Determination of Emissivity and Heat Transfer Coefficient. Rev. Sci. Instrum. 2013, 84 (2), 024902. https://doi.org/10.1063/1.4790471.

(4) Kholghy, M. R.; Veshkini, A.; Thomson, M. J. The Core-Shell Internal Nanostructure of Soot - A Criterion to Model Soot Maturity. Carbon 2016, 100, 508-536. https://doi.org/10.1016/j.carbon.2016.01.022. 
(5) Smooke, M. D.; McEnally, C. S.; Pfefferle, L. D.; Hall, R. J.; Colket, M. B. Computational and Experimental Study of Soot Formation in a Coflow, Laminar Diffusion Flame. Combust. Flame 1999, 117 (1), 117-139. https://doi.org/10.1016/S0010-2180(98)000960 .

(6) Saffaripour, M.; Veshkini, A.; Kholghy, M.; Thomson, M. J. Experimental Investigation and Detailed Modeling of Soot Aggregate Formation and Size Distribution in Laminar Coflow Diffusion Flames of Jet A-1, a Synthetic Kerosene, and n-Decane. Combust. Flame 2014, 161 (3), 848-863. https://doi.org/10.1016/j.combustflame.2013.10.016.

(7) Yan, W.; Lou, C. Two-Dimensional Distributions of Temperature and Soot Volume Fraction Inversed from Visible Flame Images. Exp. Therm. Fluid Sci. 2013, 50, 229-233. https://doi.org/10.1016/j.expthermflusci.2013.05.013.

(8) Liu, F.; Thomson, K. A.; Smallwood, G. J. Soot Temperature and Volume Fraction Retrieval from Spectrally Resolved Flame Emission Measurement in Laminar Axisymmetric Coflow Diffusion Flames: Effect of Self-Absorption. Combust. Flame 2013, 160 (9), 1693-1705. https://doi.org/10.1016/j.combustflame.2013.02.007.

(9) Rutherford, J. W.; Dawson-Elli, N.; Manicone, A. M.; Korshin, G. V.; Novosselov, I. V.; Seto, E.; Posner, J. D. Excitation Emission Matrix Fluorescence Spectroscopy for Combustion Generated Particulate Matter Source Identification. Atmos. Environ. 2020, 220, 117065. https://doi.org/10.1016/j.atmosenv.2019.117065.

(10) Sun, R.; Zobel, N.; Neubauer, Y.; Cardenas Chavez, C.; Behrendt, F. Analysis of GasPhase Polycyclic Aromatic Hydrocarbon Mixtures by Laser-Induced Fluorescence. Opt. Lasers Eng. 2010, 48 (12), 1231-1237. https://doi.org/10.1016/j.optlaseng.2010.06.009.

(11) Kim, D.; Kumfer, B. M.; Anastasio, C.; Kennedy, I. M.; Young, T. M. Environmental Aging of Polycyclic Aromatic Hydrocarbons on Soot and Its Effect on Source Identification. Chemosphere 2009, 76 (8), 1075-1081. https://doi.org/10.1016/j.chemosphere.2009.04.031.

(12) Wang, H. Formation of Nascent Soot and Other Condensed-Phase Materials in Flames. Proc. Combust. Inst. 2011, 33 (1), 41-67. https://doi.org/10.1016/j.proci.2010.09.009.

(13) Gould, T.; Larson, T.; Stewart, J.; Kaufman, J. D.; Slater, D.; McEwen, N. A Controlled Inhalation Diesel Exhaust Exposure Facility with Dynamic Feedback Control of PM Concentration. Inhal. Toxicol. 2008, 20 (1), 49-52. https://doi.org/10.1080/08958370701758478. 